\title{
Numerical modeling of bottom trawling-induced sediment transport and accumulation in La Fonera submarine canyon, northwestern Mediterranean Sea
}

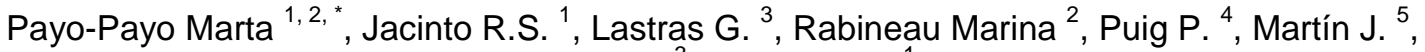 \\ Canals M. ${ }^{3}$, Sultan Nabil ${ }^{1}$
}

${ }^{1}$ IFREMER, Géosciences Marines-EDROME, Centre de Brest, BP70, CS10070, 29280 Plouzané, France

${ }^{2}$ Université de Brest, IUEM, UMR CNRS 6538, Domaines Océaniques, Place Nicolas Copernic, 29280

Plouzané, France

${ }^{3}$ CRG Marine Geosciences, Department de Dinàmica de la Terra i dels Oceans, Universitat de

Barcelona, E-08028 Barcelona, Spain

${ }^{4}$ Institute of Marine Sciences, CSIC, E-08003 Barcelona, Spain

${ }^{5}$ Centro Austral de Investigaciones Científicas (CADIC-CONICET), Bernardo Houssay 200, V9410CAB

Ushuaia, Tierra del Fuego, Argentina

*Corresponding author : Marta Payo-Payo, email address : marta.payo.payo@ifremer.fr

\begin{abstract}
:
Bottom trawling leads to recurrent sediment resuspension events over fishing grounds. Recent studies have shown how bottom trawling can drive seascape reshaping at large spatial scales and enhance sediment transport in submarine canyons, which subsequently impacts deep-sea ecosystems. Present knowledge on the transfer and accumulation of sediment flows triggered by bottom trawling is based on localized and infrequent measurements whilst a more complete picture of the process is needed. The present work focuses on the modeling of sediment transport and accumulation resulting from trawling activities in La Fonera submarine canyon, northwestern Mediterranean Sea, thus contributing to an improved assessment of trawling impacts. Based on mooring data within a canyon gully, we use an inverse model to retrieve the unknown time series of resuspension due to trawling over the fishing grounds. This resuspension is later used as forcing for the direct problem: we simulate trawling-induced flows through the canyon and provide a 3D visualization of potential trawling impacts on sediment dynamics, including the identification of the propagation patterns of sediments resuspended by trawling. Flows coming from shallower fishing grounds are funneled through canyon flank gullies towards the canyon axis, with part of the resuspended sediment reaching the continental rise out of the canyon across the open continental slope. Trawling-induced sediment flows promote sediment accumulation beyond the canyon mouth. Given the wide geographical distribution of bottom trawling, our results have far-reaching implications that go much beyond La Fonera submarine canyon. Our study represents a starting point for the assessment of the sedimentary impact of bottom trawling in deep continental margins.
\end{abstract}




\section{Highlights}

- A novel framework for estimating bottom-trawling sediment resuspension and transport is provided.

- The results yield a spatial view of submarine canyon sediment dynamics and sedimentation patterns.

- Model results are in good agreement with in situ data and sedimentation rates.

Keywords: Bottom trawling, Inverse model, Modeling, Sediment transport, Submarine canyon, Turbidity currents 


\section{Introduction}

Bottom trawling is a non-selective fishing technique involving the towing of heavy collecting devices to harvest living resources. Bottom trawling is a widespread activity with a global trawled surface of up to $22 \times 10^{6} \mathrm{~km}^{2}$ (WRI, 2001) with $40 \%$ of this activity extending beyond the continental shelf-break; this is a surface equivalent to twice the surface of Europe. At present, bottom trawling may be considered one of the anthropogenic activities with a stronger and more widespread impact on the seafloor due to its recurrence, intensity, mobility and wide geographical extent (Eastwood et al., 2007; Benn et al., 2010; Puig et al. 2012; Martín et al., 2014a). Demersal fisheries, and bottom trawling among them, have extended their activity from traditional shallow fishing grounds towards the continental slope and further offshore (Haedrich et al., 2001; Morato et al., 2006). This forced expansion is due to the depletion of shallow coastal resources as well as to the development of new and more powerful engines and heavier and larger gears allowing the exploitation of previously inaccessible resources. Also, the adoption of Exclusive Economic Zones (EEZ) since the seventies has pushed fisheries offshore beyond the 200 nautical miles from coastal baselines. Government subsidies have also favored the offshore expansion of deep fisheries (Sumaila et al., 2008, 2010; Martín et al., 2014a). Artificial disturbances of the seafloor tend to be more severe and long-lasting in deep sea environments than in shallow environments due to their lower resilience and higher vulnerability to external disturbances (e.g. Pusceddu et al., 2014). Natural processes such as waves and storms able to overcome human imprints are weaker in the former (Dyerkjaer et al., 1995). Thus, the more 
powerful engines combined with heavier and larger gear which are employed at greater depths have an enhanced impact on the deep seafloor (Martín et al., 2014a and references therein). Trawling-induced sediment resuspension and transport, or the initiation of trawling-induced sediment gravity flows, are not fully investigated and understood. Present knowledge is based on seldom and geographically localized direct observations from shallow environments and continental shelves (Churchill, 1989; Palanques et al., 2001; Durrieu de Madron et al., 2005; Dellapenna et al., 2006; Ferré et al., 2008), monitoring surveys in the wake of trawl gears (O’Neill and Summerbell, 2011; O'Neill et al., 2013), numerical modeling of the physical impact of the gear on the seabed (Prat et al., 2008; Ivanović et al., 2011; Esmaeli et Ivanović, 2014) and time series analysis from moored instruments (Palanques et al., 2005; Puig et al., 2012; Martín et al., 2014b). A better understanding and prediction of trawling impact would allow the development of methodologies to assess the biological and environmental effects of fishing and the design of low impact gears (Diesing et al., 2013; Depestele et al., 2015). Process-based models can complete insight into physical processes in deep environments but are rarely applied in such systems on a wide scale.

In the present paper, a numerical process-based model developed to reproduce underwater sediment-laden flows is implemented in La Fonera canyon (hereafter LFC, also known as Palamós), in the northwestern Mediterranean Sea, an area where extensive bottom trawling takes place. The consequences in terms of sediment fluxes (i.e. suspended sediment concentration and current speed) have been monitored at several depths within the water column by means of an instrumented mooring (Puig et al., 2012; Martín et al., 2014b).

In order to better understand the temporal and spatial propagation of trawling induced turbidity currents, the resuspension of sediment due to trawling needs to be determined. As such, two 4 
problems are presented and analyzed in the present manuscript (Fig.1): an inverse model, in order to retrieve the resuspension due to trawling, and a direct problem, the numerical simulation of the sediment transfer from the fishing grounds to deeper water sites. The inverse problem allows us to determine the three major unknowns related to the triggering mechanism of turbidity currents: area of influence, transfer function (i.e., response at MGM to different events over the fishing grounds previously defined) and resuspension $\left(R_{S}\right)$ over the fishing grounds. The estimated resuspension issued by the inverse problem is used as forcing in the direct problem.

\section{Regional setting}

\subsection{Physiography, hydrodynamics and sediment transport}

LFC runs about $110 \mathrm{~km}$ from $80 \mathrm{~m}$ down to $2550 \mathrm{~m}$ depth (Fig. 2) (Amblas et al., 2006). Its head is deeply incised in the $30 \mathrm{~km}$ wide North Catalan continental shelf, with its axis located deeper than $1200 \mathrm{~m}$ at the equivalent position of the shelf break. The western canyon rim is only about 2-3 $\mathrm{km}$ from the coastline, with the tip of its western branch at barely $800 \mathrm{~m}$ (Palanques et al., 2005; Lastras et al., 2011). The canyon head presents a N-S orientation whilst the main canyon axis is orientated WNW-ESE. The canyon walls are steep (over $25^{\circ}$ ) and indented by numerous gullies (Lastras et al., 2011).

Two hydrosedimentary domains have been identified within the canyon (Palanques et al., 2005; Martín et al., 2006): an "inner" domain, up to $1200 \mathrm{~m}$ depth, and an "outer" domain. In the first one the closed circulation is dominated by the influence of the topography and the sediment inputs from the adjacent shelf whilst in the second one the slope dynamics and the seasonal trends play a major role on particle fluxes (Palanques et al., 2005; Martín et al., 2006). The main feature of the regional circulation is a slope current referred to as the Northern Current (Millot, 
1999), which flows from the Ligurian Sea to the Gulf of Lions (GoL) and then southwards over the continental slope off Catalonia. The microtidal environment of the area facilitates studying the dynamics of the currents within the canyon and its interactions with topography. The closeness of the canyon head to the shore and its incision on the continental shelf allows the canyon to capture the sediments from littoral drift, major storms and dense shelf water cascading (DSWC) via both its head and northern flank (Lastras et al., 2011; Ribó et al, 2011; Canals et al., 2013).

\subsection{Anthropogenic forcing}

Deep-sea trawling has been conducted along the flanks of LFC since the early $20^{\text {th }}$ century (Alegret and Garrido, 2008). The local fleet targets the deep sea shrimp Aristeus antennatus (Riso 1816). Trawling activities are conducted on the canyon flanks mainly from 200 to $800 \mathrm{~m}$ depth along three main fishing grounds: Sant Sebastià and Llevant on the northern flank and Rostoll on the southern flank. Fishing is more intense between $400 \mathrm{~m}$ and $750 \mathrm{~m}$ (Company et al., 2008; Puig et al., 2012; Martín et al., 2014c). The otter trawl gears employed by the local vessels present heavy doors (400-1300 kg) that spread apart approximately $100 \mathrm{~m}$ while fishing (Palanques et al., 2006). Previous studies have revealed the importance of trawling-induced sediment resuspension and associated flows on the near-bottom turbidity and on the sediment dynamics in this canyon (Palanques et al., 2006; Martín et al., 2014b). It has been shown that chronic trawling along the rims of this canyon has resulted in significant modification of the seascape (Puig et al., 2012).

Mooring observations revealed the occurrence of frequent peaks in suspended sediment concentration (SSC) and sharp increases in near-bottom velocity (Palanques et al., 2005, 2006; 
Martín et al., 2007). Since these bursts always occurred on working days and hours, and not under rough sea conditions, they were related to turbidity currents associated to bottom trawling activities along the northern canyon flank. Such trawling-induced turbidity currents were initially recorded in 2001 with a mooring located $12 \mathrm{~m}$ above the bottom in the canyon axis at $1200 \mathrm{~m}$ depth, (P2 in Fig. 2c) reaching velocities of $\sim 25 \mathrm{~cm} / \mathrm{s}$ and SSCs of $\sim 35 \mathrm{mg} / \mathrm{l}$, but were not recorded at a mooring located at $1700 \mathrm{~m}$ depth in the canyon axis at a deeper position (P4 in Fig. 2c) (Palanques et al., 2005, 2006; Martín et al., 2007). Mooring data showed that currents only affected a limited part of the canyon and sediment did not travel too far along the canyon axis. Isolated turbidity currents observed in the records at $1700 \mathrm{~m}$ depth in the canyon axis were associated with slope failures from the untrawled southern canyon flank (Martín et al., 2007).

In 2011, an instrumented mooring (hereafter MGM, from Montgrí gully mooring, Fig. 2c) was placed inside the tributary gully of Montgrí at $980 \mathrm{~m}$ depth. The position of deployment, $200 \mathrm{~m}$ below the limit of the Sant Sebastià fishing ground on the northern flank, was limited by the operational working depth of the instrumented mooring. A tight coupling was observed between the temporal distribution of high turbidity events and the working schedule of the local fleet, with turbidity currents observed repeatedly on weekdays during working hours. Maximum velocities of up to $38 \mathrm{~cm} / \mathrm{s}$ at $12 \mathrm{~m}$ above seafloor and SSCs of $236 \mathrm{mg} / \mathrm{l}$ at $5 \mathrm{~m}$ above seafloor were recorded (Puig et al., 2012; Martín et al., 2014b)

The effects of trawling were found to extend beyond the fishing grounds, modifying sediment accumulation rates in the lower canyon (Martín et al., 2008). A sediment core (P4 in Fig. 2c) retrieved in 2002 from the canyon axis at $1700 \mathrm{~m}$ depth allowed the identification of two sedimentary regimes. The upper part of the core showed a fine layering corresponding to enhanced sediment accumulation that allowed the preservation of physical structures. The lower 7 
part records a relatively slow accumulation and significant bioturbation. The transition from nonlaminated to laminated sediments in the cores coincides with a two-fold increase in the sediment accumulation rate linked to the rapid technical development and increase in the engine power undergone by the local trawling fleet in the seventies. A recent study that analyzed a sediment core at the same site 9 years later, suggests that the accumulation rate during the last decade has dramatically increased and could approach $2.4 \mathrm{~cm} / \mathrm{yr}$ (Puig et al., 2015).

\section{Data and tools}

\subsection{In situ data}

A 100 m resolution bathymetric grid was generated from a compilation of bathymetric data from French and Spanish research institutions and has been included in the model (Fig. 2c).

In situ monitoring data are used to calibrate the inverse model and to reliably reproduce sediment resuspension due to trawling. Current velocity and suspended sediment concentration data (Puig et al., 2012) from MGM (41 $52.49^{\prime} N ; 3^{\circ} 20.66^{\prime} E$, Fig. 2c) has been used to construct a synthetic time series of instantaneous sediment transport through integration over the vertical of the available dataset.

The area of the fishing fleet over the canyon flanks is defined on the basis of navigation tracks recorded by the Vessel Monitoring System (VMS) between the years 2007 and 2010 provided by the Fishing Monitoring Centre of the Spanish Secretariat of Marine Fishing (SEGEMAR). The data depict two active fishing grounds in the zone: Sant Sebastià and Llevant on the northern flank and Rostoll on the southern flank (Fig. 3a). A straight line delimits the NE border of the 
fishing grounds as resuspension here was deemed not to influence MGM dynamics where data are available.

Surface sediment near MGM corresponds to silty mud with sand content less than $3 \%$. However, in the trawled areas, previous studies have described an upward coarsening trend and a sorting of grains (Martín et al., 2014a, 2014c). A grain solid density $\left(\rho_{s}\right)$ of $2600 \mathrm{~kg} / \mathrm{m}^{3}$ is considered for the sediment in the area.

\subsection{Numerical model}

We implement Nixes-TC (Jacinto and Burel, 2003), a numerical process-based model developed to reproduce underwater sediment-laden flows, to LFC. The model follows the principles of those developed by Parker et al. (1986) and Bradford and Katopodes (1999). The spatial development of an unsteady turbidity current flowing in deep ambient fluid (Fig. 4) can be described by the following set of vertically integrated partial differential equations derived by (Parker et al., 1986): the vertically integrated fluid, momentum and sediment conservation equations. Key improvements of Nixes-TC are the inclusion of the sedimentation model (settling velocity) in the equation of flux conservation, together with the development of a non-linear flow-dependent shear stress coefficient valid for all Reynolds numbers from laminar to fully turbulent flows.

\subsubsection{Equations and processes included}

The continuity and momentum equations at the basis of the model are virtually identical to the shallow water equations with the exception of the hydrostatic thrust. In our case, the inertial pressure is still given by Bernoulli's principle (i.e. pressure is proportional to the loss of kinetic 
energy along a streamline; however, the deviation from hydrostatic pressure is given by the reduced specific gravity of the particles. The slow-varying slope between the different grid elements justifies the use of the hydrostatic pressure approximation since variations from hydrostatic pressure can be considered as negligible. We use the Boussinesq approximation, which implies that the effect of density difference between the turbidity current and the ambient fluid is neglected in the acceleration terms but kept in the gravity terms, where it drives the flow.

Equations forming the basis of the model are the fluid continuity equation, the momentum conservation in $x$ and $y$ and the sediment mass conservation. The horizontal coordinates $x$ and $y$ and the upward normal coordinate $\mathrm{z}$ are assumed to be boundary-attached coordinates along the ocean bed. The system of equations can be written in flux vector form (Bradford et al., 1997) as:

$$
\frac{\partial U}{\partial t}+\frac{\partial \boldsymbol{F}}{\partial x}+\frac{\partial \boldsymbol{G}}{\partial y}=\boldsymbol{Q}
$$

where $\boldsymbol{U}$ is the vector of conservative variables, $\boldsymbol{F}$ and $\boldsymbol{G}$ are the flux vectors in x and y direction respectively, and $\boldsymbol{Q}$ is the vector containing the source terms:

$\boldsymbol{U}=\left(\begin{array}{c}h \\ U_{x} h \\ U_{y} h \\ h C\end{array}\right)$

$\boldsymbol{F}=\left(\begin{array}{c}U_{x} h \\ U_{x}^{2} h+\frac{1}{2} R C g h^{2} \\ U_{x} U_{y} h \\ U_{x} h C\end{array}\right)$

$\boldsymbol{G}=\left(\begin{array}{c}U_{y} h \\ U_{x} U_{y} h \\ U_{y}^{2} h+\frac{1}{2} R C g h^{2} \\ U_{y} h C\end{array}\right)$ 


$$
\boldsymbol{Q}=\left(\begin{array}{c}
e_{w} \sqrt{U_{x}^{2}+U_{y}^{2}}-w_{s} \\
-R C g h S_{x}-C_{D} U_{x} \sqrt{U_{x}^{2}+U_{y}^{2}} \\
-R C g h S_{y}-C_{D} U_{y} \sqrt{U_{x}^{2}+U_{y}^{2}} \\
w_{s}\left(p E_{s}-C_{b}\right)
\end{array}\right)
$$

where $h$ is the flow thickness, $U_{x}$ and $U_{y}$ are the layer-averaged velocities in the $x$ and $y$ directions respectively, $C$ is the layer-averaged suspended sediment concentration, $R=\left(\rho_{s}-\right.$ $\rho) / \rho$ is the submerged specific gravity, where $\rho_{s}$ is the grain solid density and $\rho$ the density of the ambient fluid, $S_{x}=\tan \alpha_{x}$ and $S_{y}=\tan \alpha_{y}$ are the bottom slope in the $x$ and $y$ directions, $g$ is the acceleration due to gravity, $u_{*}$ is the shear velocity, $e_{w}$ is the ambient fluid entrainment coefficient derived by Parker et al. (1987), $E_{S}$ is the sediment entrainment coefficient developed by Garcia and Parker $(1991,1993), C_{D}$ is the coefficient of bed friction, $w_{S}$ is the settling velocity, $(1-p)$ is the porosity of the sediment and $C_{b}$ is the near-bed sediment concentration. In our simulations we consider $C_{b}=C$.

The inclusion of a sedimentation model $\left(w_{s}\right)$ in the equation of continuity is one of the novelties of Nixes-TC and enables the existence of equilibrium solutions. It arises from the definition of $h$ as the vertical scale of the TC and hence, the thickness over which sediment is present. Since $h$ can be defined as twice the average position of the particles, the variation of the average position of the particles of sediment will give the variation of $h$. Physically, as in a 3D formulation there must be a balance, between vertical turbulent mixing (here water entrainment) and sediment settling fluxes (here settling velocity). The settling velocity $w_{s}$ in the model is function of the settling velocity in clear water. The settling velocity of sediment with grain diameter $D$ is computed by the Zanke's formula (Zanke, 1977) that extends the Stokes' law for larger particles: 
$w_{S, w}=10 \frac{v}{D} \sqrt{1+\frac{0.01\left(\frac{\rho_{S}}{\rho}-1\right) g D^{3}}{v^{2}}}$

The contribution of bed shear stress to motion is expressed by the quadratic formulation $\tau_{b x}=$ $\rho C_{D} U_{x} \sqrt{U_{x}^{2}+U_{y}^{2}}$ and $\tau_{b y}=\rho C_{D} U_{y} \sqrt{U_{x}^{2}+U_{y}^{2}}$ in the $x$ and $y$ directions. At equilibrium conditions (i.e. $\mathrm{Fr}_{\mathrm{d}}=\frac{\mathrm{U}}{\sqrt{R g C h}}=1$ ) the driving force of the slope must be compensated by the bed shear. Hence, $C_{D}$ is not constant and it may change as much as the forcing slope, with values ranging between $10^{-3}$ and $10^{-2}$ for turbulent flows as shown in Figure 5. The bed drag depends on the local properties of the flow: Reynolds number Re and relative roughness $k_{s} / h$, where $k_{s}$ is the bed roughness associated to the grain sediment size and it is defined as $k_{s}=D$. Provided that the local flow properties may change at every time step and from one grid to another, $C_{D}$ is calculated at every time step for every grid point. It includes the contribution of viscosity and turbulence to the bed shear stress, thus it is valid for all Reynolds numbers from laminar to fully turbulent. Figure 5 shows the evolution of $C_{D}$ depending on Reynolds number for different relative roughness $\left(\mathrm{k}_{\mathrm{s}} / \mathrm{h}\right)$.

Nixes-TC includes an equation of bed continuity (equation (3)), similar to Exner equation, although here the sediment flux is vertical.

$\frac{\partial z}{\partial t}=\frac{D-E}{1-\gamma}$

Where $\partial z / \partial t$ is the temporal evolution of the bed, $D-E$ is the net vertical flux of sediment onto the bed $\left(w_{s} C_{b}-w_{s} p E_{s}\right)$ and $\gamma$ is the porosity of the bed. 


\subsubsection{Numerical scheme}

The Volume Finite Method permits evaluating the coupled system of nonlinear hyperbolic partial differential equations provided by Bradford et al. (1997) and Bradford and Katopodes (1999). Source terms are calculated following an implicit scheme. The Riemann problem at each interface is solved following Roe (1981). The typical boundary condition of open outflow boundary is used in the present study. The implementation of the boundary conditions is accomplished through the use of a ghost cell (outside the domain of interest) at the boundary. The reflection of the concentration, current thickness and velocities perpendicular and parallel to the wall are placed in the ghost cell (i.e. concentration, current thickness and perpendicular and horizontal velocity remain unchanged). These non-reflective open outflow boundaries ensure that information can freely exit the computational domain without causing disturbances of to the solution. The implicit numerical scheme ensures that numerical instability does not occur as implicit algorithms can cope with sharp changes in solution by using reduced time steps. The condition of stability is the Courant-Friedrichs-Levy (CFL) condition.

Inputs of the model are the orthogonal grid corresponding to the bathymetry of the canyon, sediment properties (i.e. grain size, fraction of a given sediment grain size and density) and initial deposit (i.e. volume concentration and porosity) which will be equivalent to an initial sediment resuspension. The kinematic viscosity and density of water as well as the von Karman coefficient for the turbulence closure are also included in the parameters file. Initial and boundary conditions are provided to the model in terms of position, mass and volume of sediment remobilized (i.e. trawled area and remobilization due to trawling). Outputs of the model are the values of current thickness, current velocity (streamwise and transverse direction) and 
sediment concentration at each grid point. These variables allow the calculation of mass flux and instantaneous sediment transport, bed shear stress and spatial distribution of sedimentary deposit.

\section{The inverse problem: assessment of the triggering mechanism}

Resuspension fluxes due to trawling are not fully understood. The assessment of trawling disturbances and trawling-induced resuspension requires quantifying the rate at which trawls inject sediment into the water column, the height of the plume generated by the trawl gear and the rate at which this plume fades (Durrieu de Madron et al., 2005).

Trawling activity is patchy both in time and space. The trawl gear ploughs furrows along the towpath leading to sediment remobilization. Seabed disturbance is simultaneous to sediment cloud release into the water column (Fig. 6a). However, the effective quantity of sediment resuspended by trawling in deep environments remains largely unknown. The parameters that allow the quantification of trawling impact over the fishing grounds show variation of one order of magnitude according to studies conducted in shallow environments. Trawling resuspension depends on the characteristics of the gear, the nature of the sediment and towing speed (Durrieu de Madron et al., 2005). The penetration depth $\left(P_{f}\right)$ of the trawl in the sediment depends on the gear component and while the heavier parts, such as the otter doors that keep the net open, will

penetrate down to several centimeters; others, such us the sweep lines, will only skim some millimeters of the seafloor surface (Schwinghamer et al., 1998; Dellapenna et al., 2006; O’Neill and Summerbell, 2011). The rate at which sediment plumes are released and fade depends on the sediment's clay content (Durrieu de Madron et al., 2005; Ivanović et al., 2011). The height (h) of sediment plumes after a trawler's passage on soft bottom sediments on continental shelves varies between 5 and $10 \mathrm{~m}$ (Churchill, 1989; Durrieu de Madron et al., 2005). The towing speed $\left(V_{T}\right)$ 14 
also influences the sediment release and can vary during fishing hauls with common values between 2 and 5 knots (He and Winger, 2010). The amount of sediment remobilized by a trawler in fishing operation is given by the surface trawled per unit of time and the depth scraped (Fig. 6b). Since we lack information about the trawling resuspension fluxes over the fishing grounds and given the wide range of values and uncertainties in the variables involved, we consider a mean value of resuspension $\left(R_{S}\right)$ spread over the whole fishing grounds under consideration. This approach averages the uncertainties while providing a more general picture of the sediment dynamics in the canyon. The resuspension is expressed in terms of equivalent remobilized sediment thickness and is considered to be instantaneously injected in the water column and uniformly resuspended over the first $10 \mathrm{~m}$ above the bottom in the water column (Churchill, 1989) (Fig. 6c). This initial height allows us to take into account the scale of turbulence, which is given by the fishing gear size. The volume concentration of the sediment plume released is calculated by means of mass conservation (equation (4)) between the sediment scrapped from the bed layer (i.e. left part of the equation) and the sediment injected into the water column (i.e. right part of the equation):

$C_{d} \cdot R_{s}=C_{s} \cdot h$

where $C_{d}$ is the volumetric concentration of the sediment in the bed, $R_{S}$ is the sediment thickness remobilised, $C_{S}$ is the volumetric concentration of the sediment cloud and $h$ is the height of the sediment cloud. In our simulations we consider a value of $C_{d}=0.25(650 \mathrm{~g} / 1)$. 
4.1. Influence of the depth reached by trawlers in the sediment transport in MGM/Definition of the area of influence (i.e. critical depth) of the trawling fleet

A first set of simulations was performed to define the area of influence of the local trawling fleet and to determine the critical depth from which trawling-induced turbidity currents develop down the canyon reaching MGM. For all the simulations an initial homogeneous instantaneous remobilization is considered over the northern continental shelf, upper continental slope and canyon flank at an increasing range of depths. The shallower area considered reached the $200 \mathrm{~m}$ isobath, the second area increased the depth considered to $300 \mathrm{~m}$ and so on in $100 \mathrm{~m}$ increments until a depth of $800 \mathrm{~m}$. (Fig. 3b). The $200 \mathrm{~m}$ isobath roughly corresponds to the canyon rim depth, thus restricting trawling to the continental shelf, whilst in the trawled area down to $800 \mathrm{~m}$ it covers both this part of the continental shelf and the canyon flank. The $800 \mathrm{~m}$ isobath defines the limit of actual trawling activity over the northern canyon flank. The initial sediment thickness considered is $1 \mathrm{~cm}$ provided the mean scraped depth values given in previous studies (Churchill, 1989; Durrieu de Madron et al., 2005), which is equivalent to a volumetric concentration of $\Phi_{s}=2.5 \cdot 10^{-4}(0.65 \mathrm{~g} / \mathrm{l})$. A grain size of $63 \mu \mathrm{m}$ is considered since no significant differences were observed in the sensitivity tests performed for the range of values corresponding to silt (Supplementary Figure 1).

Turbidity currents do not reach the MGM mooring site when trawling is limited to the shelf at less than $200 \mathrm{~m}$ water depth (Fig. 7). Shallower than this depth threshold, bottom trawling increases local turbidity without sediment laden flows developing down the continental slope due to the shelf's low gradient.

\subsection{Development of the transfer function}

A second set of simulations for different initial events was carried out. Remobilization is imposed over the fishing grounds (Fig. 3a) defined on the basis of VMS data for the period 20072010. The resulting area is a conservative estimation of the potential area that can be bottom 
trawled. The remobilized thickness $\left(R_{S}\right)$ ranges from $0.1 \mathrm{~cm}$ to $0.75 \mathrm{~cm}$ and is considered to be instantaneously injected in the water column and uniformly resuspended over the first $10 \mathrm{~m}$ above the bottom. These values correspond, according to equation (4), to resuspended sediment concentrations of $0.065 \mathrm{~g} / \mathrm{l}$ and $0.4875 \mathrm{~g} / \mathrm{l}$ respectively and trigger turbidity currents that, at the location of MGM, display values of instantaneous sediment transport of the same order of magnitude as those measured. Two functions are derived from this exercise: (i) a transfer function $f(t-\tau)$, and (ii) an amplitude function $A\left(R_{S}\right)$. The transfer function contains information about the response of the system at MGM to an event over the fishing grounds (i.e. temporal evolution and time scale). The transfer function is obtained by means of normalization of the responses at MGM for the different initial conditions. The application of a moving average filter with a window size of $600 \mathrm{~s}$ allows the removal of undesired noise associated with the combination of the different signals. The maximum window size applied is limited by the time lag between the first peak and the first valley and by the time lag of the arrival of the response at MGM, this is to say, $2100 \mathrm{~s}$. The amplitude function contains information about the forcing imposed. The amplitude function relating amplitude at MGM and remobilization over the fishing grounds is found through spline fitting. The instantaneous transport $\left(M_{m p}(t)\right)$ at MGM at a time $t$ caused by a punctual remobilization $R_{s}$ over the fishing grounds at a time $\tau_{o}$ is given by the product of both functions.

$M_{m p}(t)=A\left(\tau_{o}\right) \cdot f\left(t-\tau_{o}\right)$

Similar responses are obtained for different initial conditions over the fishing grounds considered (Fig. 8a). Each event of resuspension over the fishing grounds triggers a response at MGM that appears to last about 16 hours (Fig. $8 \mathrm{a}$ and 8c). There is a time lag of about 30 ' between the 
remobilization over the canyon flanks and arrival time at MGM (Fig. 8a and 8c). The peak of the event reaches MGM at about 90' after the remobilization (Fig. 8a and 8c). The similar responses obtained for each individual event in terms of time scale and the fact that response amplitudes are proportional to the forcing allow the decomposition of the signal into two functions: a quasilinear relationship (Fig. 8b) between the remobilization $\left(R_{S}\right)$ over the fishing grounds (i.e. forcing) and the amplitude $(A)$ of the response at MGM, and a transfer function (Fig. 8c) containing the physical processes and time scales inherent to the system. By splitting the response of an event of resuspension into these two functions (i.e. transfer function and relationship $A \propto R_{S}$ ), we isolate the part of the response at MGM due to the system itself (i.e. transfer function) and the part of the response due to the external forcing (i.e. relationship $A \propto$ $\left.R_{S}\right)$.

\subsection{Inverse analysis model}

Our aim is to quantify the unknown sediment removal $R_{S}(t)$ along the fishing grounds that would cause turbidity events comparable to those measured in 2011 at MGM. To do so, we use an inverse analysis model, i.e. a model that calculates from a set of observations the causal factors that produce them. Our set of observations is the data measurements $M(t)$ at MGM, and the causal factor is the sediment remobilization over the fishing grounds $R_{s}(t)$. Our inverse model is based on the previously determined functions for a single event (i.e. transfer function $f(t-\tau)$ and amplitude function $=g\left(R_{S}\right)$. The signal obtained at MGM is considered as linear superposition of $\mathrm{n}$ discrete instantaneous remobilization events over the fishing grounds (Fig. 9).

Each one of these events condenses the remobilization associated to its $60 \mathrm{~s}$ window, implying that resuspension is expressed in terms of equivalent thickness removal per minute. The modeled 
instantaneous sediment $\left(M_{m}(t)\right)$ transport at MGM is given by the convolution of the transfer function and the different amplitudes.

$M_{m}(t)=\int_{0}^{t} A(\tau) \cdot f(t-\tau) d \tau$

By linearizing and discretizing the problem, we are able to relate the discrete data measurements $(M(t))$ at the mooring site to the discrete inverse model parameters (i.e. unknown amplitude of the different events $A(\tau))$. The comparison between measurements $(M(t))$ and inverse model output $\left(M_{m}(t)\right)$ at MGM allows us to infer the amplitude $A(\tau)$ of the different events at MGM and due to the relationship $A_{o} \propto R_{S}$ (see Fig. 8b), we can infer the latter.

$M(t)=M_{m}(t)$

The left part of the previous expression $M(t)$ is the synthetic series of instantaneous sediment transport $\left(\mathrm{kg} / \mathrm{m}^{2}\right)$ obtained from the dataset measured at MGM. The right part of the equation (7) $M_{m}(t)$ is the instantaneous sediment transport issued by the inverse model obtained through linear superposition of the different punctual events modeled.

The aim of the inverse modeling is to retrieve the amplitude $(A(\tau))$ of the $\mathrm{n}$ different events that will allow us to infer the forcing over the fishing grounds $\left(R_{S}\right)$. However, $A(\tau)$ is largely unknown and multiple solutions are possible. In order to reduce the degrees of freedom of the system we follow two alternative approaches to determine the discrete inverse model parameters $A(\tau)$ and hence, infer the time series of resuspension $R_{S}(t)$ over the fishing grounds: Gaussian distribution and Autoregressive Moving Average Model (ARMA). 


\subsubsection{Gaussian distribution}

A preliminary assessment of the impact of bottom trawling is explored by means of a Gaussian distribution of the fishing effort over the fishing grounds. This first simplified assessment is presented for illustration purposes and to evaluate the order of magnitude involved. A Gaussian distribution of the fishing effort over the two fishing grounds is considered. The relationship found between $A_{o} \propto R_{S}$ (Fig. 8b) would suggest that, in a linear approach, if the fishing effort follows a Gaussian distribution, the amplitude of the events at MGM should also follow a Gaussian distribution.

Fishing activity over the flanks of the canyon takes place on working days, whilst on Saturday and Sunday there is no activity. Vessels head offshore at 6 a.m. and head back to port at about 34 p.m. (Martín et al., 2014b). We impose the following distribution for a working day:

$A(t)=\gamma \cdot e^{-\frac{\left(t-t_{O}\right)^{2}}{2(d t)^{2}}}$

Where $t_{o}=11 \mathrm{~h}$ so that the distribution is centered at $11 \mathrm{a} . \mathrm{m}$. and its temporal window is $d t^{2}=2$. The coefficient $\gamma$ is necessary so that the response of the inverse model and the measurements at MGM are of the same order of magnitude, and takes a value of $\gamma=0.0091$. Once the time series of amplitude $A(t)$ at MGM of the different events considered is obtained, the remobilization $R_{S}$ over the fishing grounds can be inferred from the relationship $A=g\left(R_{S}\right)$ (See Fig. 8b).

Maximal resuspension values $R_{S}(t)$ of $5 \mu \mathrm{m} / \mathrm{min}$ over the fishing grounds are obtained through inverse modeling under the hypothesis of a Gaussian distribution of the fishing effort (Fig. 10a). The total volume of sediment remobilized per unit of time in the model should be equivalent to that remobilized by a reasonable fishing activity (see Fig. 6b). This maximal resuspension over 
the whole fishing grounds would be equivalent to the activity of the 22 vessels concerned by the La Fonera fisheries management plan (BOE Boletin Oficial del Estado, 2013) operating at a towing speed in the area between 2 and 3 knots scraping $3.8 \pm 0.7 \mathrm{~mm}$ on average. Despite the uncertainty in the variables involved in its calculation, these penetration depth values of the fishing gears are in the agreement with those found in the literature (Jones, 1992; Durrieu de Madron et al., 2005; Ivanović et al., 2011; O’Neill and Summerbell, 2011).

\subsubsection{Autoregressive Moving Average Model}

A more accurate assessment of the impact of bottom trawling over the fishing grounds can be determined by means of the Autoregressive Moving Average Model (ARMA) (Whittle, 1951; Box and Jenkins, 1976). The ARMA model allows splitting a signal in two parts: (i) an autoregressive part $\left(M_{A R}\right)$ expressing the inherent behavior of the system itself, and (ii) a moving average part $\left(M_{M A}\right)$ related to the external forcing of the system (i.e. the external forcing would be the time series of resuspension over the fishing grounds). The term $\varepsilon(t)$ corresponds to white noise error terms.

$M(t)=M_{A R}(t)+M_{M A}(t)+\varepsilon(t)$

$M_{A R}(t)$ explains the part of the signal due to the system itself as the output variable depends linearly on its own previous values. One can isolate the part of the signal at MGM due exclusively to the external forcing by subtracting the autoregressive part $\left(M_{A R}\right)$ as follows:

$M_{T}(t)=M(t)-M_{A R}(t)$ 
Thus, if we construct the time series of amplitude of events $A(t)$ as a function of $M_{T}(t)$, we will obtain the remobilization over the fishing grounds $R_{S}(t)$ solely associated to the external forcing (i.e. trawling).

$A(t)=\gamma \cdot g\left(M_{T}(t)\right)$

We propose the use of a polynomial $g\left(M_{T}(t)\right)=\alpha_{1} M_{T}+\alpha_{2} M_{T}^{\beta}$. This non-linear solution allows us to consider basal values and intensifies the value of the peaks.

The modeled response $M_{m}(t)$ at MGM is obtained by applying equation (7). The comparison of the measurements $M(t)$ and the inverse model $M_{m}(t)$ allows us to infer the time series of amplitudes $A(t)$. Best agreement between model outputs and measurements at MGM is found for $g\left(M_{T}(t)\right)=M_{T}^{1.3}$ and $\gamma=0.3379$. Once $A(t)$ is determined, the time series of resuspension $R_{S}(t)$ (Fig. 11a) is obtained through the relationship between the remobilization $R_{S}$ along the fishing grounds and the amplitude $A$ of the event at MGM (shown in Fig. 8b ).

This time series of trawling resuspension $R_{S}(t)$ over the fishing grounds is more accurate since in this alternative approach $A(t)$ is reconstructed as function of the forcing part $\left(M_{M A}(t)\right)$ of the signal at MGM. Values of remobilized sediment thickness greater than $0.01 \mathrm{~mm} / \mathrm{min}$ (Fig. 11a) over the fishing grounds trigger turbidity events capable of reaching MGM. The resuspension obtained through inverse model should be equivalent to that of the actual fishing fleet in the area. This uniform resuspension over the whole area would correspond to the activity of 22 vessels in the area operating at a towing speed between 2 and 3 knots and effectively scraping about $7.5 \pm 1 \mathrm{~mm}$ of sediment and injecting it into the water column. We obtain reasonable scraped depth ranges for realistic towing speeds for the actual fishing fleet in the area. Note the nonuniqueness of the solution, the number of vessels could be less but would need a deeper effective 22 
erosion to create the same observed turbidity currents. The total amount of remobilized sediment due to trawling during the period analyzed (i.e. fifteen days) is of about $1.27 \times 10^{-3} \mathrm{~km}^{3}$. Good agreement is found between the inverse model results and the measures at MGM (Fig. 11b). Pearson correlation coefficients between the re-suspension series $R_{S}(t)$ and the measurements $M(t)$ and between the results of the inverse model $M_{m}(t)$ and the measurements $M(t)$ are

$r_{X Y}\left(R_{S}(t), M(t)\right)=0.0773$ and $r_{X Y}\left(M_{m}(t), M(t)\right)=0.8381$ respectively. These respective values evidence the fact that it is the transfer function which is integrating the physical processes and time scales of the system.

\section{The direct problem: numerical modeling of trawling induced turbidity currents.}

The time series of resuspension $R_{S}(t)$ obtained through inverse modeling (Fig. 11a) is used as forcing to model the sediment dynamics and sedimentation patterns due to trawling in the canyon. The resuspension is spread over the whole fishing grounds; hence the area considered is larger than the area actually trawled at a precise instant of time. The results provided by this approach might have a larger spatial distribution than in reality.

The resuspension is integrated in the model in terms of instantaneous sediment flux over the fishing grounds, allowing us to take into account the non-linearity inherent to turbidity currents. The sediment remobilized is equivalent to an additional volume concentration that is calculated at each grid point of the area affected by trawling, taking into account the instantaneous thickness of the sediment cloud at each time step. A height cloud threshold is imposed over the fishing grounds in order to take into account the scale of the turbulence provided by the fishing 
gears. Sensitivity tests were performed for this height threshold and best results were found for $h_{\text {lim }}=1 \mathrm{~m}$. (Fig. 12). The grain size considered for the direct problem is also $63 \mu \mathrm{m}$.

This time series $R_{S}(t)$ uniformly spread over the whole fishing grounds triggers turbidity currents reaching MGM of the order of magnitude of those measured at MGM for the period analyzed between the $9^{\text {th }}$ and the $21^{\text {st }}$ June 2011 (Fig. 13). The model accurately reproduces both in time and magnitude the instantaneous sediment transport at MGM. The model is able to reproduce the sharp burst in sediment transport corresponding to the peak in the morning and the steady decay towards baseline values in the afternoon once the vessels head back to port. The good agreement found at the mooring site provides a validation of both the resuspension obtained through inverse model and of the results of the numerical model at the mooring sites.

We identify potential propagation patterns of the resuspended sediment from the fishing grounds towards the canyon axis and beyond when we force Nixes-TC with the $R_{S}(t)$ issued by the inverse modeling (see Fig. 14). The results obtained depict an overall picture of pathways and areas indirectly affected by trawling. The spatial view of the canyon sediment dynamics may improve the definition of strategic locations for mooring arrays and cores. These additional data together with a better constraint of the forcing (i.e. quantification of the sediment resuspended by each vessel in fishing operation) would enable a more realistic simulation of trawling impact. For the forcing imposed, the flow is funneled through gullies from the fishing grounds towards the canyon axis and beyond (Fig. 14 and Supplementary video MS1). A minor part of the remobilized sediment flows along the continental slope and rejoins the flow coming along the canyon axis at the glacis. 
Mean current speed over the modeled two week-period goes up to $20 \mathrm{~cm} / \mathrm{s}$ (Fig. 15) with peak values reaching up to $50 \mathrm{~cm} / \mathrm{s}$ (Fig. 16) along the canyon axis and gullies. The flow along the northern continental slope presents much lower values of current speed than those along the canyon axis and flanks. Maximum values of current speed along this northern branch of the flow go up to $25 \mathrm{~cm} / \mathrm{s}$ whilst mean values reach $0.04 \mathrm{~cm} / \mathrm{s}$. Higher values are observed in the gullies of the northern flank and along the lower canyon axis where topographic constraints are at play. Once the flow reaches the continental rise, it spreads and lower values of mean velocity are obtained.

Figure 17 shows the evolution of the flow at different locations along the LFC axis and northern canyon flank gullies (see Fig. 2c for P1 to P7 output points). There is no propagation of turbidity events associated with trawling at the point P1 at the canyon head (Fig. 17a). For other control points, depending on their location, two different types of responses are identified. On one hand, the control points located inside gullies (MGM and P3) reproduce the forcing signal with welldefined working hours and holidays (Fig. 17b). On the other hand, along the canyon axis, transport seems to be continuous during the week only reaching natural baseline levels during the weekend (Fig. 17c and d). For these points along the canyon axis, there is an increasing trend in the values of instantaneous sediment transport through the week, with baselines levels on week days in the range of half of the peak value of the previous day. We observe a time lag in the signal along the canyon axis. Instantaneous sediment transport seems more intense in the midlow canyon and in the monitored gully MGM compared to the upper canyon. The lower values of the points of cumulated sediment transport for the low canyon points are due to the time lag in the signal that prevents all the events from going through by the end of the analyzed period. Table 1 summarizes the averaged and maximum instantaneous sediment transport (i.e. $h C$, Sup. 25 
Fig. 2); the averaged and maximum sediment transport (i.e. $h C U$ ) and the cumulated sediment transport after the 15 day period analyzed for the control points.

The deposition thickness at the end of the study period is presented in Figure 18. Sediment gain on the lower part of southern canyon flank appears to be more important than on the northern wall. However these deposits and those along the canyon axis are probably ephemeral, at least in part, given the values of mean current speed. The deposition over the fishing grounds corresponds to the decantation of part of the sediment injected to simulate trawling activity. An accumulation area develops at the canyon mouth, beyond the $2000 \mathrm{~m}$ isobath, due to sediment flows propagating through the canyon axis and also those coming from the continental slope. This depocenter is coherent with the loss of transport capacity of the flow observed and with the gradients of current speed obtained. Some deposition is observed in the southern lower canyon probably due to flow overbank.

\section{Discussion}

By spreading resuspension over a potential area affected by trawling, we provide a wide picture of the trawling-induced dynamics in the canyon and show the value of numerical models in understanding deep processes associated with trawling. We propose a novel methodology based on an inverse model that allows assessing the resuspension due to trawling. Our novel approach allows us to establish the link between the trawling activity over the fishing grounds and the large-scale TC triggered by it. This resuspension is used as forcing for the numerical model to provide a large scale view of the potential impacts of trawling. We show here that numerical models can provide insight into how fast these flows move, how far they can travel and how much sediment can be carried that are difficult to achieve by punctual measurements alone. 
The results obtained in this study indicate notable differences between trawling shoreward and seaward of the $200 \mathrm{~m}$ isobath. Trawling over the flatter shallower areas can locally enhance turbidity in the water column, similarly to the observations of (Palanques et al. (2001) over the inner shelf off Barcelona; however, no sediment flows reach MGM. The results confirm previous observations in LFC (Palanques et al., 2006): it is only when fishing activity takes place on the steep slopes of the canyon flanks that trawling triggers turbidity currents. The high values of gradient slopes favor the ignition of sediment gravity flows that extend the impact of trawling beyond the fishing grounds.

We find similar responses for the different single event forcing scenarios evaluated. We separate physical processes and temporal evolution (i.e. transfer function), and intensity of the event (i.e. amplitude $A_{o}$, forcing). Our results suggest that for the identified trawled area, the intensity of the event at MGM $\left(A_{o}\right)$ is strongly determined by the initial condition $\left(R_{S}\right)$. The dynamics and temporal aspects of the flow are included in the transfer function that reproduces the behavior of turbidity currents discussed in literature (Middleton and Hampton, 1973; Kneller and Buckee, 2000) with a sharp waxing phase and a more gradual waning phase as sediment settles. Velocity and sediment concentration within the flow follow the same behavior for a single turbidity current event. The transfer function and the quasilinear relationship between the modeled amplitude at MGM and its respective initial condition, $R_{s}$, allow the linearization of the problem and are the basis of the inverse modeling.

Inverse modeling strategies have been proposed to estimate flow speed from tsunami deposits (Jaffe et Gelfenbuam, 2007; Jaffe et al., 2011), for reconstruction of deposits from turbidity currents (Lesshafft et al., 2011), and to infer paleo-flow conditions from turbidites (Falcini et al., 2009). Here the objective is not to relate deposits and flow conditions, but to obtain a forcing 27 
(i.e. resuspension over the fishing grounds) capable of triggering events similar to those measured at MGM. By using the inverse model we are able to link the trawling activity to the formation of "large-scale" turbidity currents. Our inverse model employs a novel approach based on the deconvolution of the transfer and amplitude functions previously determined. The first approximation through a Gaussian distribution of the fishing effort provides a first validation of our approach since the equivalent estimated removal of $3.8 \pm 0.7 \mathrm{~mm}$ by the fishing gears of the local trawling fleet falls in the range of values found in literature (Durrieu de Madron et al., 2005; Ivanović et al., 2011; O’Neill and Summerbell, 2011).

By using the ARMA model to isolate the part of the signal due to the external forcing $M_{M A}$, we were able to obtain a synthetic series of resuspension $R_{S}(t)$ due to trawling that triggers turbidity events reaching MGM comparable to those measured on June 2011. We observe a tight coupling between the temporal distribution of the resuspension $R_{S}(t)$ over the fishing grounds and the measured instantaneous sediment transport $M(t)$, and between the latter and the results of the inverse model $M_{m}(t)$. The inverse model accurately reproduces both phase and amplitude modulation of the instantaneous sediment transport at MGM showing an intensification of the sediment transport during the working hours of the local fishing fleet. The model presents accurate results, with a significant value of Pearson correlation coefficient of $r_{X Y}\left(M_{m}(t), M(t)\right)$ $=83.81 \%$ between model outputs $M_{m}(t)$ and measurements $M(t)$. The time series $R_{s}(t)$ would be roughly equivalent to the activity of 22 vessels in the area towing at 2 and 3 knots and effectively scraping about $7.5 \pm 1 \mathrm{~mm}$, values that are coherent with those found in the bibliography (Durrieu de Madron et al., 2005; Ivanović et al., 2011; O'Neill and Summerbell, 
2011). The accurate results obtained at MGM, together with the coherent equivalent value in terms of fishing effort and penetration of the fishing gears, validate our methodology.

The inclusion of trawling-induced resuspension as forcing in the numerical model allows the identification of transport patterns and accumulation areas. The outputs of the model for this given scenario show good agreement with the measurements at the validation point of MGM. At the canyon head (i.e. point P1, $470 \mathrm{~m}$ depth), model results show no influence of trawling, as other studies based on mooring data have already reported (Martín et al., 2007). Turbidity currents in the model seem to propagate further down than expected from previous studies (Palanques et al., 2005; Martín et al., 2006, 2007). We propose three possible explanations for this result. First, there are few measurements beyond $1700 \mathrm{~m}$ along the canyon axis, and what happens in the canyon beyond that depth remains uncertain. Second, the model only includes the turbidity current dynamics but not the general pattern of circulation in the canyon. Measurements in 2001 showed periodical inversions up and down, with low mean values at different depths ranging between 2 and $3 \mathrm{~cm} / \mathrm{s}$ and peaks reaching 20 to $40 \mathrm{~cm} / \mathrm{s}$, and net water mass flows close to the bottom directed upward (Palanques et al., 2005; Martín et al., 2006, 2007). These internal hydrodynamics of the canyon can interact with the turbidity flows and slow them down, limiting their propagation. Third, different intensities of trawling impact can be expected since the data analyzed in the present study is from a different time period to that used in previous studies. The mooring data used to infer the remobilization over the fishing grounds corresponds to measurements from 2011 whilst the mooring data in the other studies correspond to 2001. Despite the slow reduction in the number of vessels in Palamós, the local fleet underwent a dramatic increase in the installed power at the beginning of the $21^{\text {st }}$ century (Puig et al., 2015). Since the installed power is a reliable proxy of the capacity of trawlers to resuspend bottom 29 
sediments (Martín et al., 2014a), the further propagation of turbidity currents in the model for 2011 could be reasonable.

Intensification of instantaneous sediment transport is concomitant with higher mean and maximal values of current speed. This would reflect the bathymetric control on the flows while funneled through gullies. The canyon buffers transport similarly to river catchments; the signal is amplified along the canyon axis and weekend days do not imply a return to baselines values of sediment transport but to roughly half the values of the previous day. Part of the transfer of sediment from the fishing grounds to the deep takes place through the northern open continental slope following an alternative path for turbidity currents. This northern branch would interact with local along slope currents in the area with mean values of $2-4 \mathrm{~cm} / \mathrm{s}$ and peaks reaching 20 $\mathrm{cm} / \mathrm{s}$ (Palanques et al., 2005), presumably deflecting their path. Nevertheless, values of current speed and mean sediment flux are lower through this northern path than along the canyon axis indicating the canyon role as a preferential conduit of sediment transfer. The current speed (i.e. bed shear stress) along the canyon axis indicates that most of the canyon acts as a bypass where ephemeral deposits could develop and might be reintegrated by the following flows. The thickness of the deposit after 15 days of activity along the deeper canyon axis region is coherent with the high sediment rates of $2.4 \mathrm{~cm} / \mathrm{yr}$ measured for the last decade (Puig et al., 2015). The interaction of the turbidity currents with the hydrodynamics of the canyon axis can shift the accumulation areas further onshore than the results shown here. Previous studies (Martín et al., 2007; Puig et al., 2012) show a decreasing pattern in the sediment fluxes in the canyon for the spring and summer months which can be related to the higher availability of sediment on the external part of the continental shelf and the upper flanks after the winter storms. Since the time series analyzed corresponds to the beginning of the fishing season, when more sediment is 30 
available, more heavily sediment laden currents can occur. The accumulation obtained over the fishing grounds, where erosion is expected (Martín et al., 2014c), is due to the decantation of the injected sediment over this area in order to simulate the source of sediment in the model. Due to lower gradients, the flow is slower over the fishing grounds implying that at the final stage of the simulation there is still sediment in the area which has not flowed downslope (Fig. 18).

The generalization of the area, defining it as the potential area of trawling, makes our approach more generally applicable and can be considered as an upper bound of the trawling process in the canyon. However, the reasonable orders of magnitude obtained for the different variables analyzed validate our methodology.

It has been claimed that the effects of trawling on bottom sediments are not limited to the fishing grounds but can propagate further and deeper from them (Martín et al., 2008, 2014b). Our results definitely support that view and provide a spatial vision of these long-range effects. The span of these trawling-induced flows highly depends on the area over which fishing activities take place. Our methodology can help in the definition of fishing grounds with lesser physical impacts at the scale of the canyon and of the continental margin. The global extent of bottom trawling gives further-reaching implications to our methodology beyond the local study of LFC. VMS are deployed by several nations on large commercial fishing vessels (Molenaar and Tsamenyi, 2000). VMS are mandatory in the EU for vessels larger than $15 \mathrm{~m}$ and larger than 24 $\mathrm{m}$ in the USA. The application of the inverse model based on mooring data allowed us to obtain the value of resuspension over the fishing grounds defined on the basis of VMS data. Therefore, similar approaches could be followed in other regions where VMS data are available. Furthermore, the approach presented allows the definition of larger areas that could be affected 
by fishing activities taking into account the effects of bottom trawling on the sedimentary dynamics.

The application of the model provides a spatial vision of the sediment dynamics in the canyon. It enlarges the present understanding of trawling-induced sediment transfer from the fishing grounds towards deeper areas. The results obtained in terms of sediment transport provide valuable information for the definition of future mooring/coring sites that should improve the insight and knowledge of the canyon dynamics and help both to better constrain the forcing we impose in the model and with its validation. Feedback loops between field measurements and modeling are needed for an improved knowledge of turbidity current processes in general.

\section{Conclusion}

We have developed a numerical methodology to calculate the trawling resuspension over the fishing grounds and its consequences in terms of sediment transport in canyons. This novel approach is based on the definition of an area susceptible to being trawled on the basis of VMS data, inverse analysis and numerical process modeling. The key variable in trawling impact on sediment dynamics, which is the sediment remobilized, is inferred from the inverse modeling over the area defined on the basis of VMS data. The transfer and amplitude function at the basis of the inverse model allow us to link the trawling activity over the fishing activity and its effect in terms of sediment transport. Similar methodologies can be applied in other areas where trawling techniques are present. The numerical process based model validated against in situ mooring data has been used to study the sediment transfer due to trawling resuspension. The results obtained complete and enlarge the interpretations of the trawling impact on the sedimentary functioning of the canyon, since present knowledge is based on snapshots of field 
data limited in time and space. Our study allows the identification of the transfer patterns from the fishing grounds where resuspension is generated, towards the canyon axis and beyond and the associated trawling-induced accumulation areas. The canyon scale vision may help in the identification of strategic mooring and coring sites to further advance the state of our knowledge on sediment dynamics of the canyon and validate this model. The definition of trawling area based on VMS data allows identifying the potentially "damaging" and affected areas for sediment transport and would allow the identification of trawling areas with lesser impacts, with the aim of a management of fisheries not only based on the short term impact on individual species but with a more long term vision of ecosystem processes.

\section{Acknowledgments}

This work was supported by various research projects: HERMIONE (226354 and CTM201011084-E), DOS MARES (CTM2010-21810-C03), OASIS DEL MAR_Obra Social “la Caixa”, GRACCIE-CONSOLIDER (CSD2007-00067), REDECO (CTM2008-04973-E) and ABIDES (CTM2015-65142-R). We also received support from Catalan Government Grups de Recerca Consolidats grants (2009 SGR 899 and 1305). VMS data and support were provided by the Spanish General Secretariat of Maritime Fishing (SEGEMAR). Assistance at sea by the crews of RV Hespérides, RV Sarmiento de Gamboa and RV García del Cid is also acknowledged. MPP's work was supported by the "Laboratoire d'Excellence" LabexMER and co-funded by a state grant from the French government through Agence Nationale de la Recherche (ANR) under the « Investissements d'Avenir » Programme, reference ANR-10-LABX-19-01, and by a grant from the Regional Council of Brittany. Additional support was also provided by Actions-Marges Program (Mediterranée Occidentale). 


\section{References}

Alegret, J. L., and A. Garrido (2008), Historia del puerto pesquero de Palamós: migraciones, asociacionismo y desarrollo. AREAS, Rev. Int. Cienc. Soc., 27, 27-40.

Allen, S. E., and X. Durrieu de Madron (2009), A review of the role of submarine canyons in deep-ocean exchange with the shelf, Ocean Sci., 5(4), 607-620.

Amblas, D., M. Canals, R. Urgeles, G. Lastras, C. Liquete, J. E. Hughes-Clarke, J. L. Casamor, and A. M. Calafat (2006), Morphogenetic mesoscale analysis of the northeastern Iberian margin, NW Mediterranean Basin, Mar. Geol., 234(1-4), 3-20, doi:10.1016/j.margeo.2006.09.009.

BOE Boletin Oficial del Estado (2013), Orden AAA/923/2013, de 16 de mayo por la que se regula la pesca de gamba rosada (Aristeus antennatus) con arte de fondo en determinadas zonas marítimas próximas a Palamós,

Box, G. E. P., and G. M. Jenkins (1976), Time series analysis: forecasting and control, HoldenDay.

Bradford, S. F., Katapodes, N. D. and Parker, G. (1997). "Characteristic analysis of turbid underflows." Journal of Hydraulic Engineering, ASCE 123(5): 420-431.

Bradford, S. F., and N. D. Katopodes (1999), Hydrodynamics of turbid underflows. I: Formulation and numerical analysis, J. Hydraul. Eng.-Asce, 125(10), 1006-1015, doi:10.1061/(ASCE)0733-9429(1999)125:10(1006).

Churchill, J. H. (1989), The effect of commercial trawling on sediment resuspension and transport over the Middle Atlantic Bight continental shelf, Cont. Shelf Res., 9(9), 841865, doi:10.1016/0278-4343(89)90016-2.

Company, J. B., P. Puig, F. Sardà, A. Palanques, M. Latasa, and R. Scharek (2008), Climate Influence on Deep Sea Populations, PLoS ONE, 3(1), e1431, doi:10.1371/journal.pone.0001431.

Dellapenna, T. M., M. A. Allison, G. A. Gill, R. D. Lehman, and K. W. Warnken (2006), The impact of shrimp trawling and associated sediment resuspension in mud dominated, shallow estuaries, Estuar. Coast. Shelf Sci., 69(3-4), 519-530, doi:10.1016/j.ecss.2006.04.024.

Depestele, J., A. Ivanović, K. Degrendele, M. Esmaeili, H. Polet, M. Roche, K. Summerbell, L. R. Teal, B. Vanelslander, and F. G. O'Neill (2015), Measuring and assessing the physical impact of beam trawling, ICES J. Mar. Sci. J. Cons., fsv056, doi:10.1093/icesjms/fsv056.

Diesing, M., D. Stephens, and J. Aldridge (2013), A proposed method for assessing the extent of the seabed significantly affected by demersal fishing in the Greater North Sea, ICES J. Mar. Sci. J. Cons., 70(6), 1085-1096, doi:10.1093/icesjms/fst066.

Durrieu de Madron, X., B. Ferré, G. Le Corre, C. Grenz, P. Conan, M. Pujo-Pay, R. Buscail, and O. Bodiot (2005), Trawling-induced resuspension and dispersal of muddy sediments and dissolved elements in the Gulf of Lion (NW Mediterranean), Cont. Shelf Res., 25(19-20), 2387-2409, doi:10.1016/j.csr.2005.08.002. 
Dyerkjaer, S. M., J. K. Jensen, and E. Hoffmann (1995), Mussel dredging and effects on the marine environment, ICES CM 95/ E:13.

Eastwood, P. D., C. M. Mills, J. N. Aldridge, C. A. Houghton, and S. I. Rogers (2007), Human activities in UK offshore waters: an assessment of direct, physical pressure on the seabed, ICES J. Mar. Sci. J. Cons., 64(3), 453-463, doi:10.1093/icesjms/fsm001.

Esmaeili, M., and A. Ivanović (2014), Numerical modelling of bottom trawling ground gear element on the seabed, Ocean Eng., 91, 316-328, doi:10.1016/j.oceaneng.2014.08.014.

Falcini, F., M. Marini, S. Milli, and M. Moscatelli (2009), An inverse problem to infer paleoflow conditions from turbidites, J. Geophys. Res. Oceans, 114(C10), C10019, doi:10.1029/2009JC005294.

Ferré, B., X. Durrieu de Madron, C. Estournel, C. Ulses, and G. Le Corre (2008), Impact of natural (waves and currents) and anthropogenic (trawl) resuspension on the export of particulate matter to the open ocean: Application to the Gulf of Lion (NW Mediterranean), Cont. Shelf Res., 28(15), 2071-2091, doi:10.1016/j.csr.2008.02.002.

Garcia, M., and G. Parker (1991), Entrainment of Bed Sediment into Suspension, J. Hydraul. Eng.-Asce, 117(4), 414-435, doi:10.1061/(ASCE)0733-9429(1991)117:4(414).

Garcia, M., and G. Parker (1993), Experiments on the Entrainment of Sediment into Suspension by a Dense Bottom Current, J. Geophys. Res.-Oceans, 98(C3), 4793-4807, doi:10.1029/92JC02404.

Haedrich, R. L., N. R. Merrett, and N. R. O’Dea (2001), Can ecological knowledge catch up with deep-water fishing? a North Atlantic perspective, Fish. Res., 51(2-3), 113-122, doi:10.1016/S0165-7836(01)00239-9.

He, P., and P. D. Winger (2010), Effect of Trawling on the Seabed and Mitigation Measures to Reduce Impact, in Behavior of Marine Fishes, edited by P. He, pp. 295-314, WileyBlackwell.

Ivanović, A., R. D. Neilson, and F. G. O'Neill (2011), Modelling the physical impact of trawl components on the seabed and comparison with sea trials, Ocean Eng., 38(7), 925-933, doi:10.1016/j.oceaneng.2010.09.011.

Jacinto, R. S., and D. Burel (2003), Modélisation du devenir à court terme des boues de dragage rejetées par clapage, Rev. Fr. Génie Civ., 7(9), 1151-1166, doi:10.1080/12795119.2003.9692539.

Jaffe, B., M. Buckley, B. Richmond, L. Strotz, S. Etienne, K. Clark, S. Watt, G. Gelfenbaum, and J. Goff (2011), Flow speed estimated by inverse modeling of sandy sediment deposited by the 29 September 2009 tsunami near Satitoa, east Upolu, Samoa, Earth-Sci. Rev., 107(1-2), 23-37, doi:10.1016/j.earscirev.2011.03.009.

Jaffe, B. E., and G. Gelfenbuam (2007), A simple model for calculating tsunami flow speed from tsunami deposits, Sediment. Geol., 200(3-4), 347-361, doi:10.1016/j.sedgeo.2007.01.013.

Jones, J. (1992), Environmental-Impact of Trawling on the Seabed - a Review, N. Z. J. Mar. Freshw. Res., 26(1), 59-67.

Jordi, A., A. Orfila, G. Basterretxea, and J. Tintoré (2005), Shelf-slope exchanges by frontal variability in a steep submarine canyon, Prog. Oceanogr., 66(2-4), 120-141, doi:10.1016/j.pocean.2004.07.009. 
Kneller, B., and C. Buckee (2000), The structure and fluid mechanics of turbidity currents: a review of some recent studies and their geological implications, Sedimentology, 47, 6294, doi:10.1046/j.1365-3091.2000.047s1062.x.

Lastras, G. et al. (2011), Understanding sediment dynamics of two large submarine valleys from seafloor data: Blanes and La Fonera canyons, northwestern Mediterranean Sea, Mar. Geol., 280(1-4), 20-39, doi:10.1016/j.margeo.2010.11.005.

Lesshafft, L., E. Meiburg, B. Kneller, and A. Marsden (2011), Towards inverse modeling of turbidity currents: The inverse lock-exchange problem, Comput. Geosci., 37(4), 521-529, doi:10.1016/j.cageo.2010.09.015.

Martín, J., A. Palanques, and P. Puig (2006), Composition and variability of downward particulate matter fluxes in the Palamós submarine canyon (NW Mediterranean), J. Mar. Syst., 60(1-2), 75-97, doi:10.1016/j.jmarsys.2005.09.010.

Martín, J., A. Palanques, and P. Puig (2007), Near-bottom horizontal transfer of particulate matter in the Palamós Submarine Canyon (NW Mediterranean), J. Mar. Res., 65(2), 193218.

Martín, J., P. Puig, A. Palanques, P. Masqué, and J. García-Orellana (2008), Effect of commercial trawling on the deep sedimentation in a Mediterranean submarine canyon, Mar. Geol., 252(3-4), 150-155, doi:10.1016/j.margeo.2008.03.012.

Martín, J., P. Puig, A. Palanques, and A. Giamportone (2014a), Commercial bottom trawling as a driver of sediment dynamics and deep seascape evolution in the Anthropocene, Anthropocene, 7, 1-15, doi:10.1016/j.ancene.2015.01.002.

Martín, J., P. Puig, A. Palanques, and M. Ribó (2014b), Trawling-induced daily sediment resuspension in the flank of a Mediterranean submarine canyon, Deep Sea Res. Part II Top. Stud. Oceanogr., 104, 174-183, doi:10.1016/j.dsr2.2013.05.036.

Martín, J., P. Puig, P. Masqué, A. Palanques, and A. Sánchez-Gómez (2014c), Impact of Bottom Trawling on Deep-Sea Sediment Properties along the Flanks of a Submarine Canyon, PLoS ONE, 9(8), e104536, doi:10.1371/journal.pone.0104536.

Middleton, G. V., and M. A. Hampton (1973), Part I. Sediment Gravity Flows: Mechanics of Flow and Deposition, , 1-38.

Millot, C. (1999), Circulation in the Western Mediterranean Sea, J. Mar. Syst., 20(1-4), 423442, doi:10.1016/S0924-7963(98)00078-5.

Molenaar, E., and M. Tsamenyi (2000), Satellite-based Vessel Monitoring Systems. International legal aspects and developments in state practice, FAO United Nations.

Morato, T., R. Watson, T. J. Pitcher, and D. Pauly (2006), Fishing down the deep, Fish Fish., 7(1), 24-34, doi:10.1111/j.1467-2979.2006.00205.x.

O'Neill, F. G., and K. Summerbell (2011), The mobilisation of sediment by demersal otter trawls, Mar. Pollut. Bull., 62(5), 1088-1097, doi:10.1016/j.marpolbul.2011.01.038.

O’Neill, F. G., S. M. Simmons, D. R. Parsons, J. L. Best, P. J. Copland, F. Armstrong, M. Breen, and K. Summerbell (2013), Monitoring the generation and evolution of the sediment plume behind towed fishing gears using a multibeam echosounder, ICES J. Mar. Sci. J. Cons., 70(4), 892-903, doi:10.1093/icesjms/fst051.

Palanques, A., J. Guillén, and P. Puig (2001), Impact of bottom trawling on water turbidity and muddy sediment of an unfished continental shelf, Limnol. Oceanogr., 46(5), 1100-1110, doi:10.4319/lo.2001.46.5.1100. 
Palanques, A. et al. (2005), General patterns of circulation, sediment fluxes and ecology of the Palamós (La Fonera) submarine canyon, northwestern Mediterranean, Prog. Oceanogr., 66(2-4), 89-119, doi:10.1016/j.pocean.2004.07.016.

Palanques, A., J. Martín, P. Puig, J. Guillén, J. B. Company, and F. Sardà (2006), Evidence of sediment gravity flows induced by trawling in the Palamós (Fonera) submarine canyon (northwestern Mediterranean), Deep Sea Res. Part Oceanogr. Res. Pap., 53(2), 201-214, doi:10.1016/j.dsr.2005.10.003.

Parker, G., Y. Fukushima, and H. M. Pantin (1986), Self-accelerating turbidity currents, J. Fluid Mech., 171, 145-181, doi:10.1017/S0022112086001404.

Parker, G., M. Garcia, Y. Fukushima, and W. Yu (1987), Experiments on turbidity currents over an erodible bed, J. Hydraul. Res., 25(1), 123-147, doi:10.1080/00221688709499292.

Prat, J., J. Antonijuan, A. Folch, A. Sala, A. Lucchetti, F. Sardà, and A. Manuel (2008), A simplified model of the interaction of the trawl warps, the otterboards and netting drag, Fish. Res., 94(1), 109-117, doi:10.1016/j.fishres.2008.07.007.

Puig, P., M. Canals, J. B. Company, J. Martín, D. Amblas, G. Lastras, A. Palanques, and A. M. Calafat (2012), Ploughing the deep sea floor, Nature, 489(7415), 286-289, doi:10.1038/nature11410.

Puig, P., J. Martín, P. Masqué, and A. Palanques (2015), Increasing sediment accumulation rates in La Fonera (Palamós) submarine canyon axis and their relationship with bottom trawling activities, Geophys. Res. Lett., 42(19), 2015GL065052, doi:10.1002/2015GL065052.

Pusceddu, A., S. Bianchelli, J. Martín, P. Puig, A. Palanques, P. Masqué, and R. Danovaro (2014), Chronic and intensive bottom trawling impairs deep-sea biodiversity and ecosystem functioning, Proc. Natl. Acad. Sci., 201405454, doi:10.1073/pnas.1405454111.

Ribó, M., P. Puig, A. Palanques, and C. Lo Iacono (2011), Dense shelf water cascades in the Cap de Creus and Palamós submarine canyons during winters 2007 and 2008, Mar. Geol., 284(1-4), 175-188, doi:10.1016/j.margeo.2011.04.001.

Roe, P. L. (1981), Approximate Riemann solvers, parameter vectors, and difference schemes, $J$. Comput. Phys., 43(2), 357-372, doi:10.1016/0021-9991(81)90128-5.

Sanchez-Vidal, A., et al. (2012), Impacts on the deep-sea ecosystem by a severe coastal storm, PLOS ONE, 7 (1), e30395, doi: 10.1371/journal.pone.0030395.

Sumaila, U. R., L. Teh, R. Watson, P. Tyedmers, and D. Pauly (2008), Fuel price increase, subsidies, overcapacity, and resource sustainability, ICES J. Mar. Sci. J. Cons., 65(6), 832-840, doi:10.1093/icesjms/fsn070.

Sumaila, U. R., A. Khan, L. Teh, R. Watson, P. Tyedmers, and D. Pauly (2010), Subsidies to high seas bottom trawl fleets and the sustainability of deep-sea demersal fish stocks, Mar. Policy, 34(3), 495-497, doi:10.1016/j.marpol.2009.10.004.

Whittle, P. (1951), Hypothesis testing in time series analysis., Almqvist \& Wiksells boktr., Uppsala.

WRI (2001), World Resources 2000-2001 | World Resources Institute, World Resources Institute.

Zanke, U. (1977), Berechnung der Sinkgeschindigkeiten von Sedimenten, Mitt. des FranziusInstituts für Wasserbau, Heft46, Seite 243, Technical University, Hannover, West Deutschland. 


\section{TABLE CAPTION}

Table 1. Averaged and maximum and cumulated instantaneous sediment transport for the control points analyzed.

\section{FIGURE CAPTION}

Figure 1. Flow chart showing the two different problems analyzed (i.e. inverse problem and direct problem) and the methodology applied in each case. For each phase of the work flow, methods are shown in the left column and output on the right column.

Figure 2. Location of La Fonera submarine canyon. (a) The study area is located in the Mediterranean Sea. (b) Bathymetric map of the northwestern Mediterranean Sea. GoL: Gulf of Lion, GoR: Gulf of Roses. The red rectangle represents the extension of the modeling domain in this study. (c) Bathymetric data used for numerical modeling. Red stars indicate the position of the mooring site (MGM) and output points (P1-P7) analyzed. The white rectangle represents the zoom over the fishing grounds provided in Fig. 3.

Figure 3. Fishing grounds considered in the present study. (a) Fishing grounds of Rostoll (southern flank) and Sant Sebastià and Llevant (northern flank) defined on the basis of VMS data. (b) The analyzed fishing grounds extend over the continental shelf and towards La Fonera canyon axis reaching different depths from the canyon rims $(200 \mathrm{~m})$ to the isobaths of $800 \mathrm{~m}$ that defines the limit of real trawling activity over the northern canyon flank.

Figure 4. Definition sketch of a turbidity current flowing from left to right in deep ambient fluid. Major processes taken into account are included as well as vertical profiles of concentration and velocity. The sketch is presented for a two dimensional current for simplicity.

Figure 5. Bed friction coefficient $\left(C_{d}\right)$ as a function of the Reynolds number $(R e)$ for different relative roughness ( $\mathrm{k}_{\mathrm{s}} / \mathrm{h}$, where $\mathrm{k}_{\mathrm{s}}$ is the bed roughness and $\mathrm{h}$ the current thickness). The range of values corresponding to turbulent flows is also indicated. 
Figure 6. Fishing trawlers characteristics and parameters: Side (a) and top (b) views of a trawler during fishing operation at a towing speed of $V_{T}$. The surface area of sediment scrapped can be estimated by the horizontal opening $\left(L_{O D}\right)$ of the otter boards multiplied by the distance $\left(V_{T} \cdot d t\right)$ travelled by the trawler by unit time $\left(L_{O D} \cdot V_{T} \cdot d t\right)$. (c) Sketch of the instantaneous release of a sediment cloud of $h$ height due to the scraping of sediment thickness $P_{f}$ by the trawler.

Figure 7. Results for the influence area of the trawling activity. (a) The fishing grounds considered cover part of the continental shelf and extend down to different depths (i.e. the trawled area considered is larger as the depth increases). The star indicates the position of the MGM mooring where the results are analyzed. (b) Outputs of the model in terms of instantaneous sediment transport $\left(\mathrm{kg} / \mathrm{m}^{2}\right)$ at MGM. The depths reached by the fishing grounds are expressed in the legend: $200 \mathrm{~m}$ depth implies trawling action over part of the continental shelf and down to $200 \mathrm{~m}$ whilst $800 \mathrm{~m}$ depth implies trawling action over part of the continental shelf and down $800 \mathrm{~m}$.

Figure 8. (a) Results in terms of instantaneous sediment transport $h C\left(\mathrm{~kg} / \mathrm{m}^{2}\right)$ at MGM for the different initial conditions analyzed. (b) Quasi-linear relationship found between the forcing (i.e. initial conditions in terms of resuspension $R_{S}$ ) imposed over the fishing grounds and the amplitude $A$ of the instantaneous sediment transport at MGM. (c) Transfer function obtained for MGM.

Figure 9. Basis of the inverse modeling applied to MGM data. The boxes on the left correspond to the forcing over the fishing grounds that we aim to determine. The boxes on the right correspond to the response at MGM to the forcing that can be obtained by the convolution of an amplitude function $A(\tau)$ and a transfer function $f(t-\tau)$. We discretize and linearize the problem by considering the forcing over the fishing grounds as a linear superposition of $n$ different events whose amplitude is unknown. From the comparison between measurements at MGM $(M(t))$ and results of the inverse model $\left(M_{m}(t)\right)$, the amplitude $A(\tau)$ of the different events at MGM can be determined. The relationship found between amplitude of the response at MGM and the forcing over the fishing grounds $\left(A_{o} \propto R_{S}\right)$ is used to infer the latter. 
Figure 10. (a) Time series of resuspension due to trawling over the fishing grounds issued by the inverse model (Gaussian approach) for the period $9^{\text {th }}$ to $21^{\text {st }}$ June 2011. (b) Measured (grey line) and inverse modeled (blue line) instantaneous sediment transport at MGM between the $9^{\text {th }}$ and the $21^{\text {st }}$ June 2011.

Figure 11. (a) Time series of resuspension due to trawling over the fishing grounds issued of the inverse model and ARMA model for the period $9^{\text {th }}$ to $21^{\text {st }}$ June 2011. Red dots represent the punctual events considered, in order to ease the visualization the envelope of the remobilization is also plotted (green line) (b) Measured (grey line) and inverse modeled (blue line) instantaneous sediment transport at MGM between the $9^{\text {th }}$ and the $21^{\text {st }}$ June 2011.

Figure 12 Sensitivity tests performed for different height cloud threshold over the fishing grounds. Outputs are presented at MGM in terms of instantaneous sediment transport $h C\left(\frac{\mathrm{kg}}{\mathrm{m}^{2}}\right)$. Modeled total flux is closer to the measurements when considering a height cloud threshold of $1 \mathrm{~m}$.

Figure 13. Measured and modeled instantaneous sediment transport at MGM for the period $9^{\text {th }}$ to $21^{\text {st }}$ June 2011. The forcing of the numerical model is the resuspension time series Rs $(\mathrm{t})$ obtained through the inverse model under the ARMA approach.

Figure 14. Modeled average sediment flux for the two-week period analyzed. The forcing imposed triggers turbidity currents reaching MGM of the same order of magnitude than those measured at MGM for period $9^{\text {th }}$ to $21^{\text {st }}$ June 2011. Note that the results obtained provide an overall picture of the potential dynamics due to trawling in the La Fonera submarine canyon.

Figure 15. Modeled average current speed over the two week period considered in La Fonera submarine canyon. The resuspension imposed over the fishing grounds provides values of instantaneous sediment transport at MGM in agreement with those measured for the period $9^{\text {th }}$ to $21^{\text {st }}$ June 2011 at MGM.

Figure 16. Modeled maximum current speed for the two week period analyzed in La Fonera submarine canyon. The resuspension imposed over the fishing grounds provides values of instantaneous sediment transport at MGM in agreement with those measured for the period $9^{\text {th }}$ to $21^{\text {st }}$ June 2011 at MGM 
Figure 17. Modeled sediment transport at different locations along the canyon axis and northern canyon flank gullies of La Fonera submarine canyon for the two-week period analyzed. The numerical model is forced with the resuspension time series $\operatorname{Rs}(\mathrm{t})$ obtained through the inverse model under the ARMA approach that triggers turbidity currents reaching MGM of the same order of magnitude than those measured at MGM for the period $9^{\text {th }}$ to $21^{\text {th }}$ June 2011 . The results are presented in terms of flux $(h C U)$ and cumulated flux $\left(\int h C U d t\right)$ on the left and right column respectively.

Figure 18. Map of modeled sediment thickness accumulated for a two week period of trawling activity. 


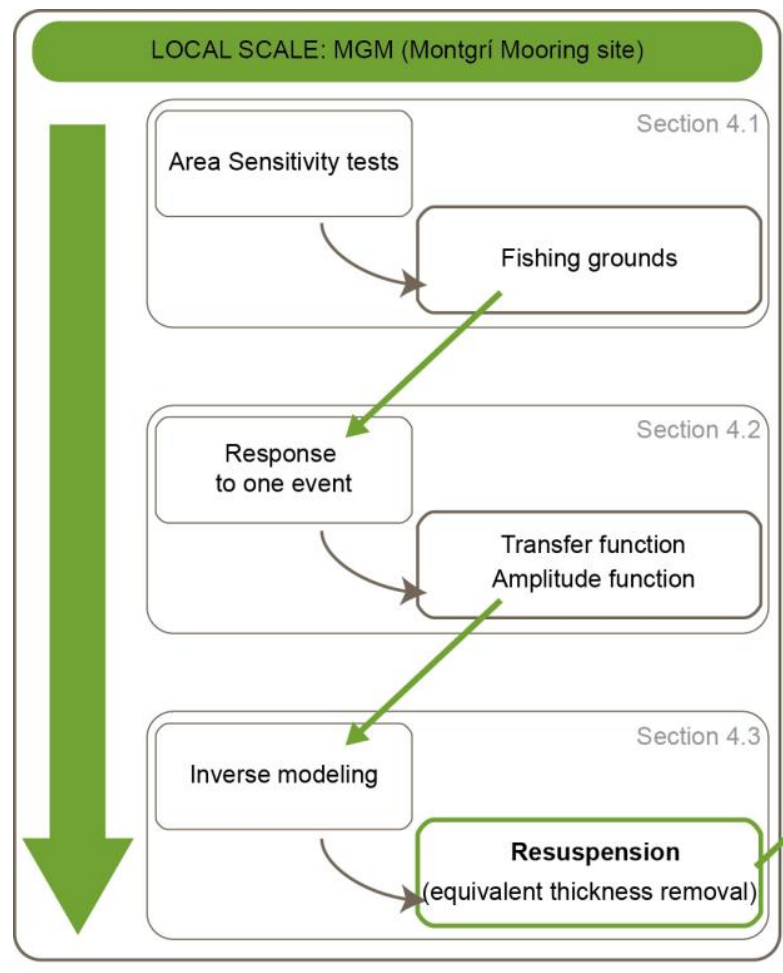

LARGE SCALE: La Fonera Canyon

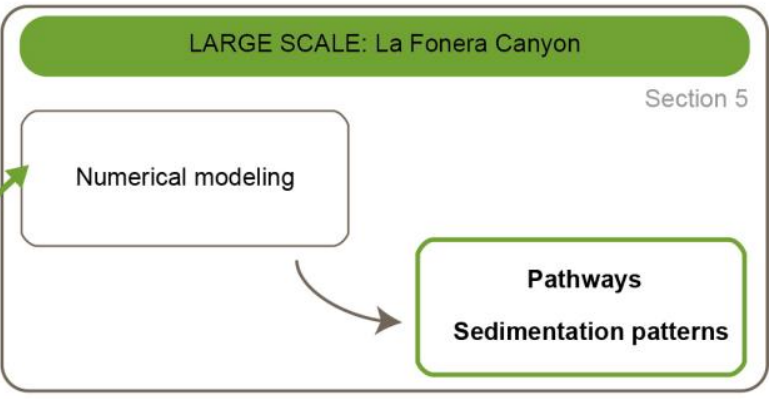

INVERSE PROBLEM

FORWARD PROBLEM

Figure 1 
a

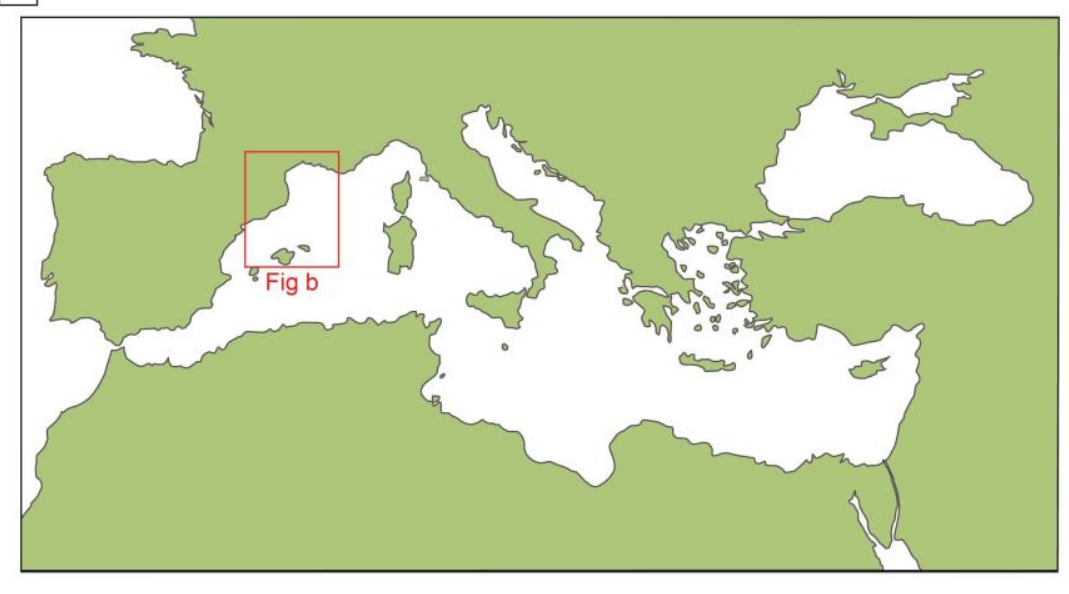

b

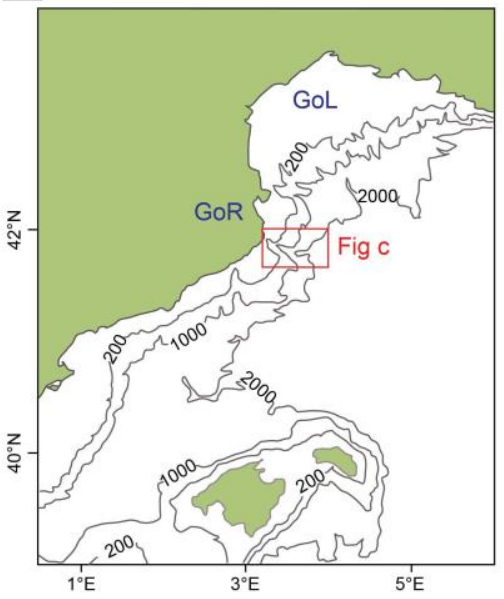

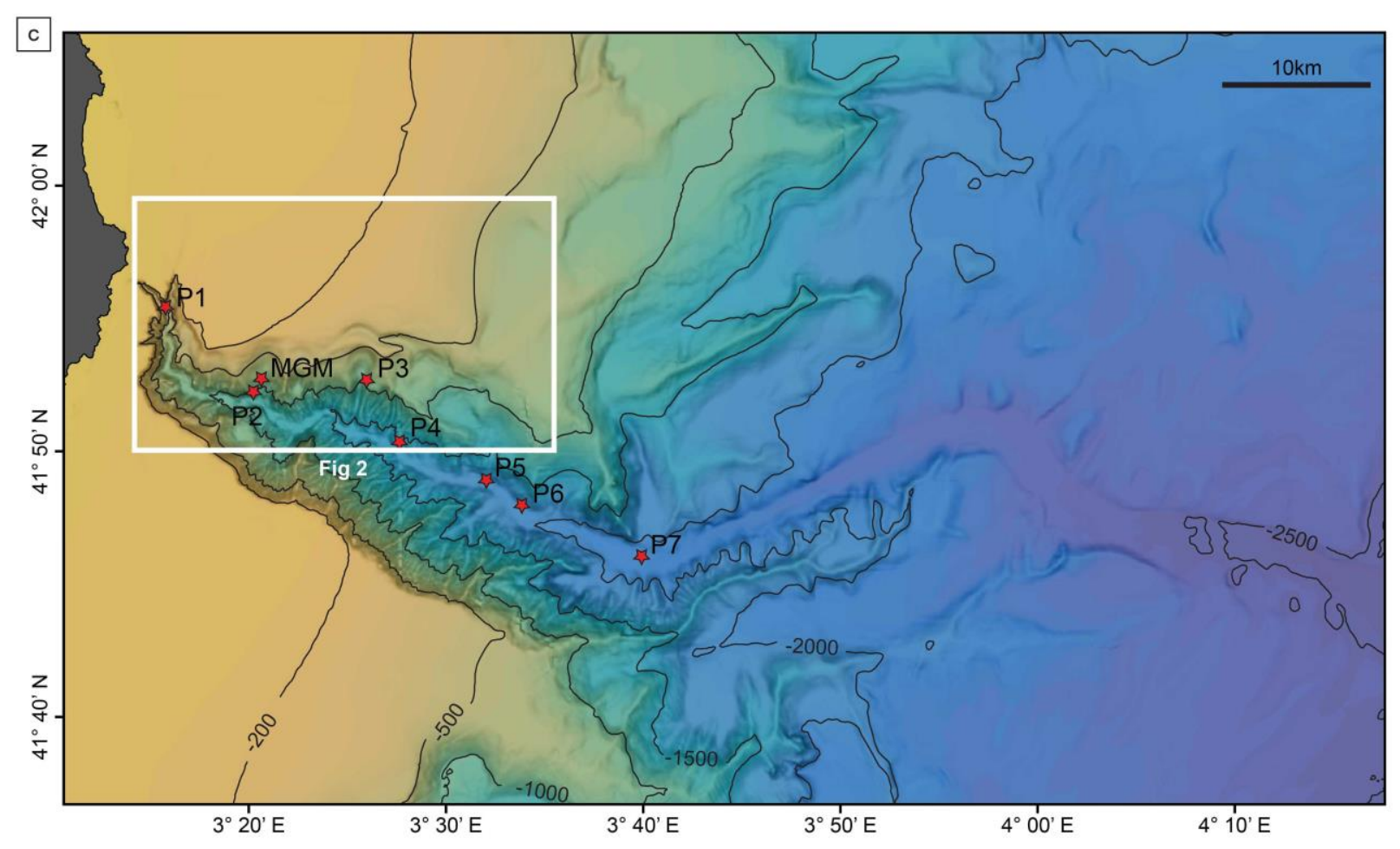

Figure 2 

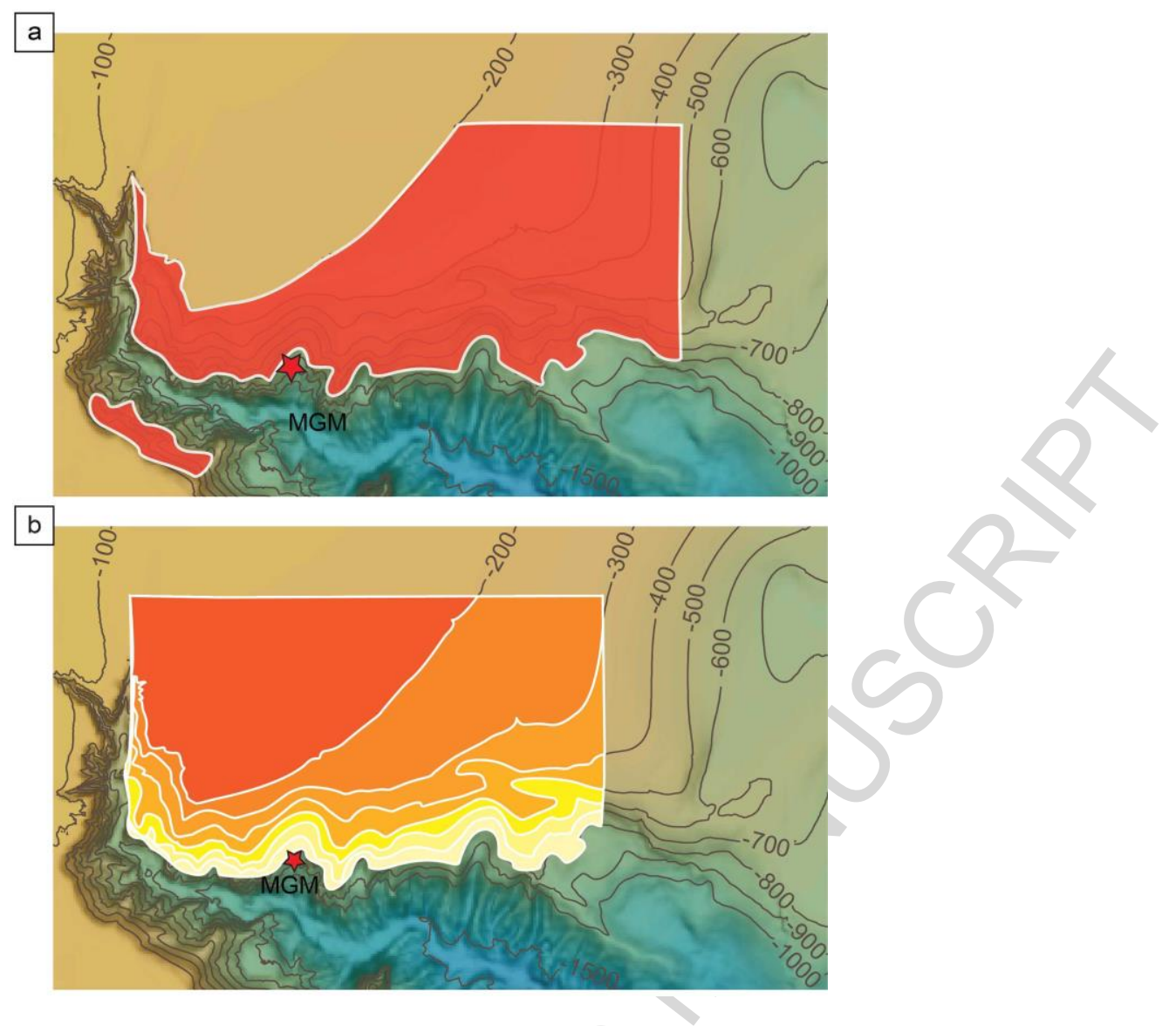

Figure 3 


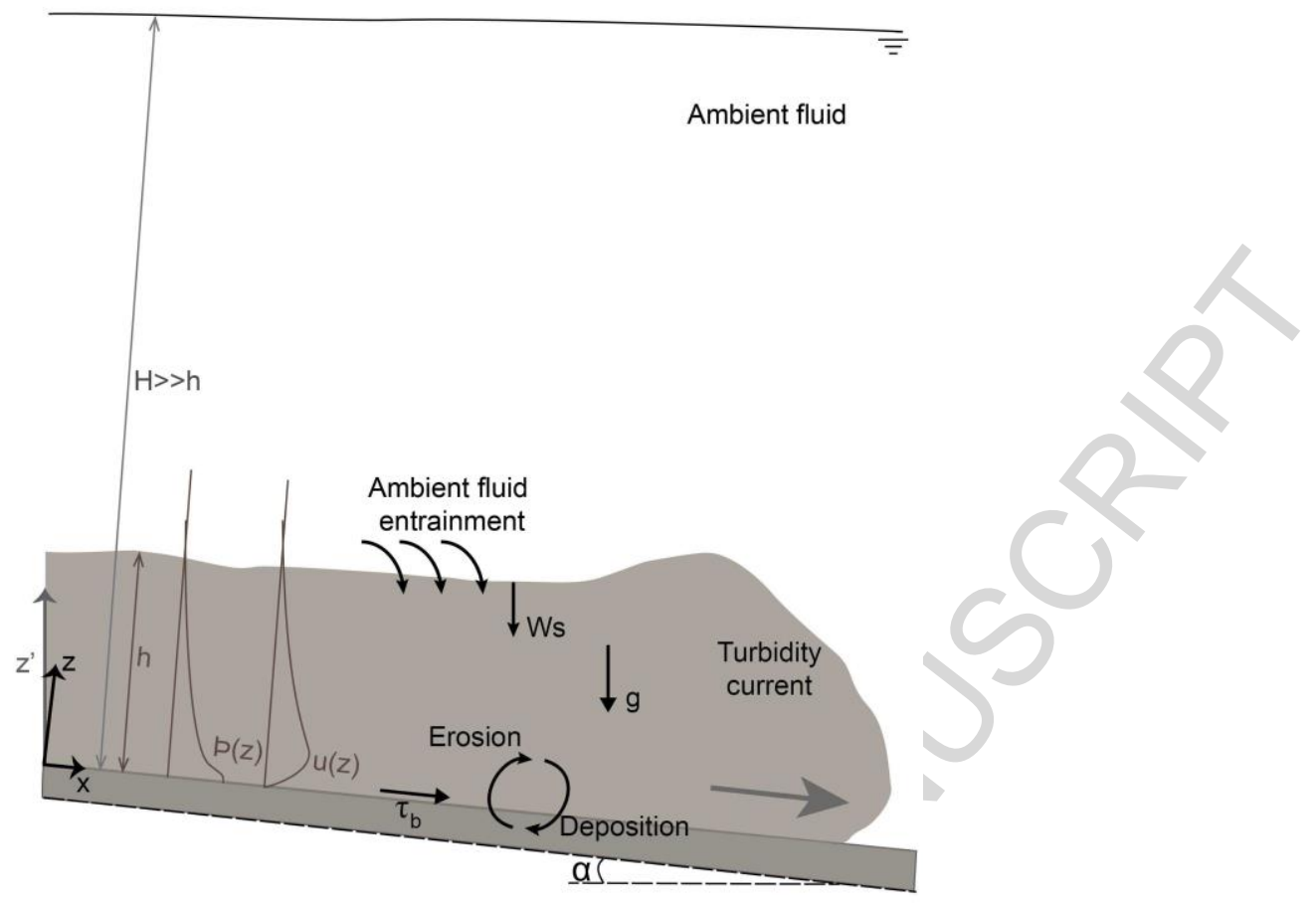

Figure 4 


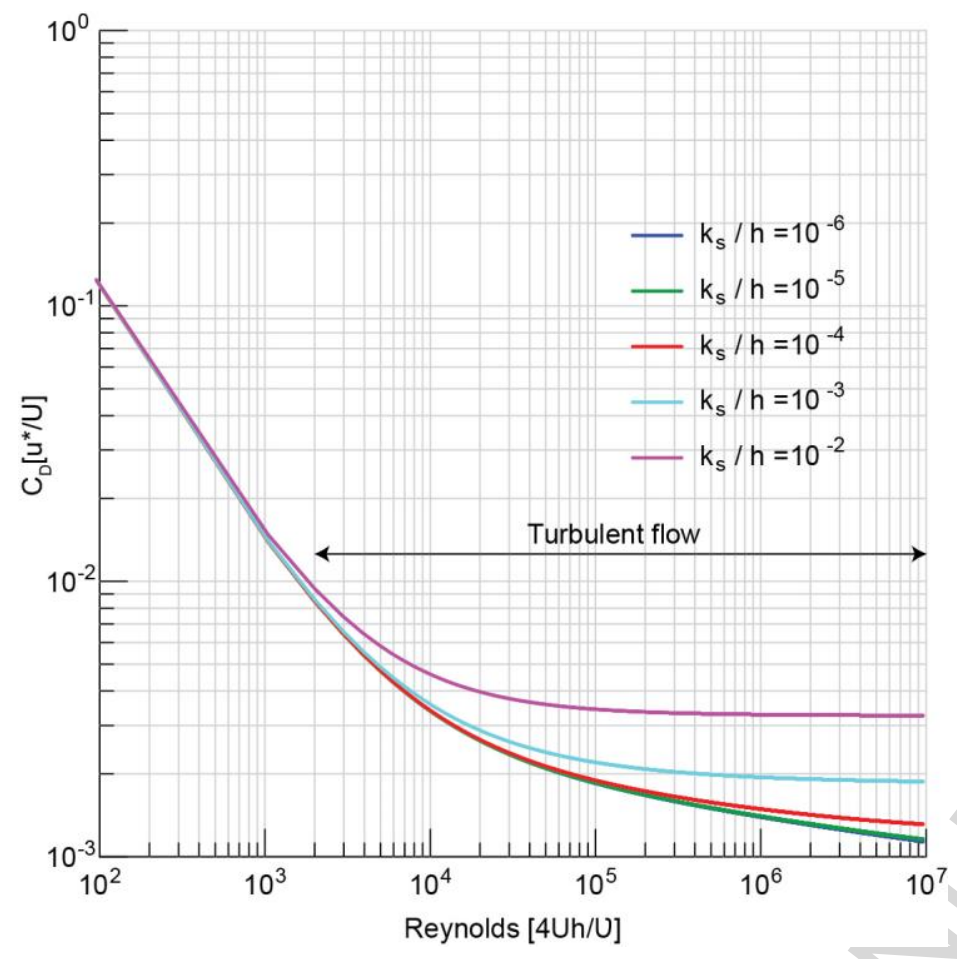

Figure 5 
a

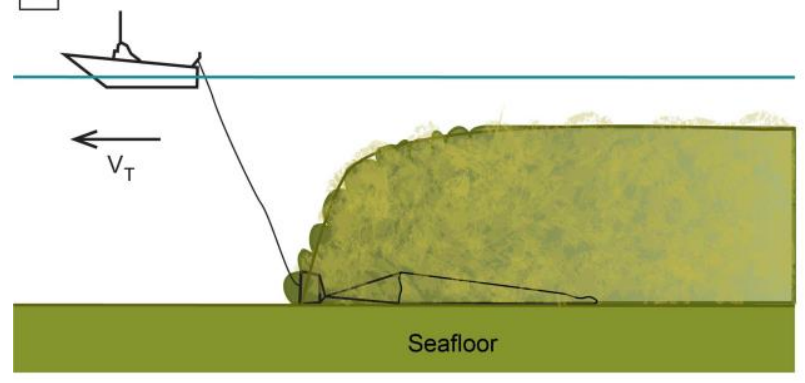

b
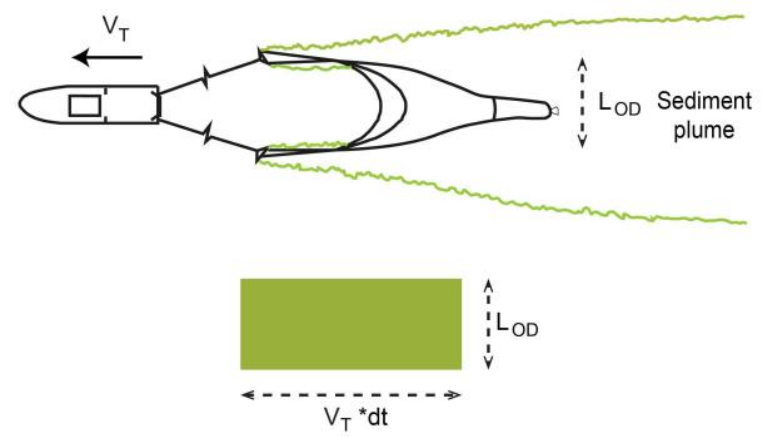

c

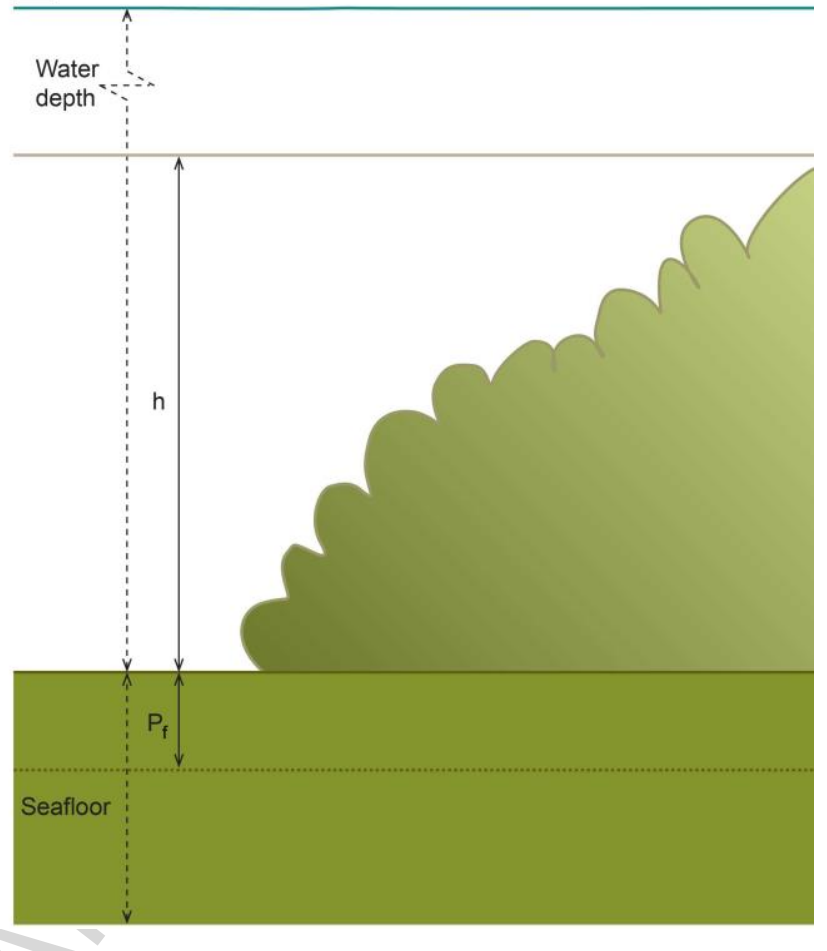

Figure 6 

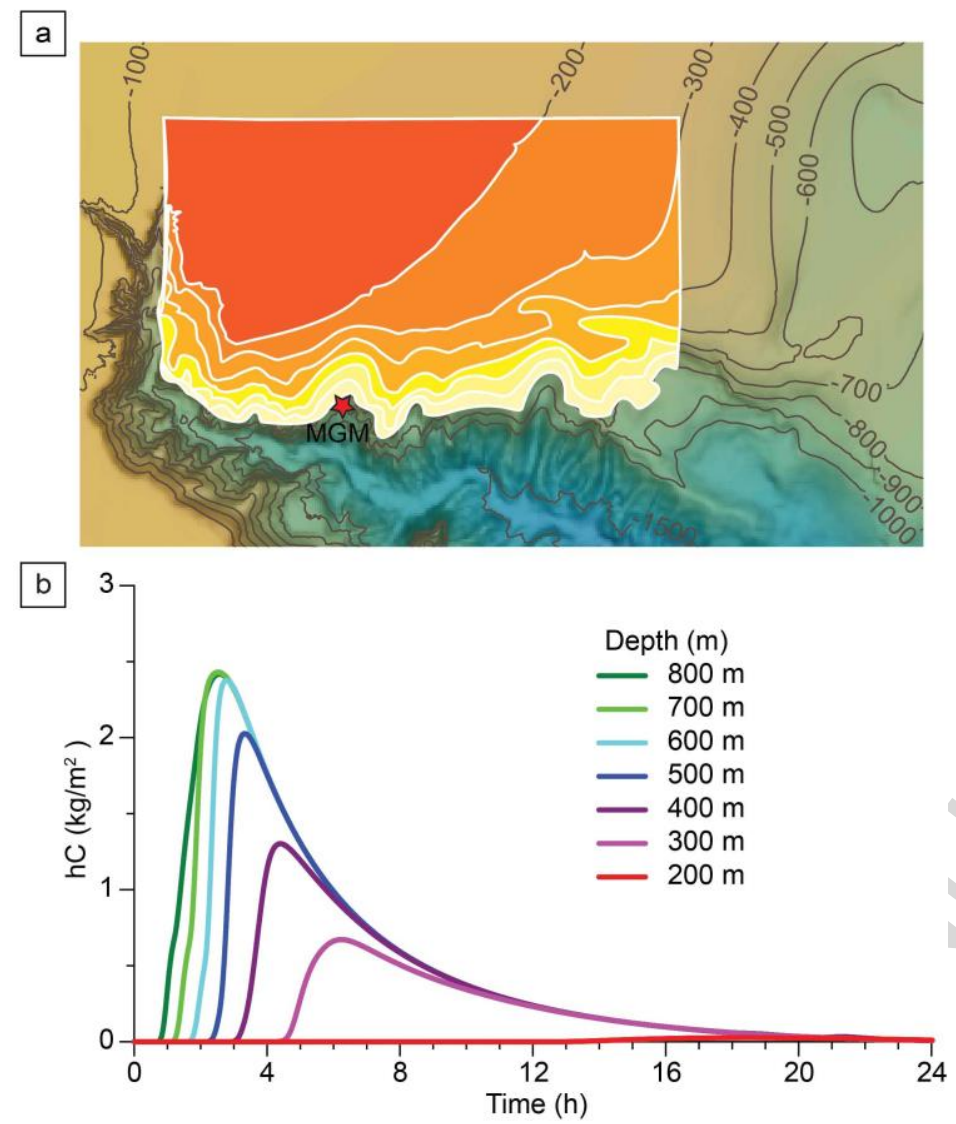

Figure 7 
a

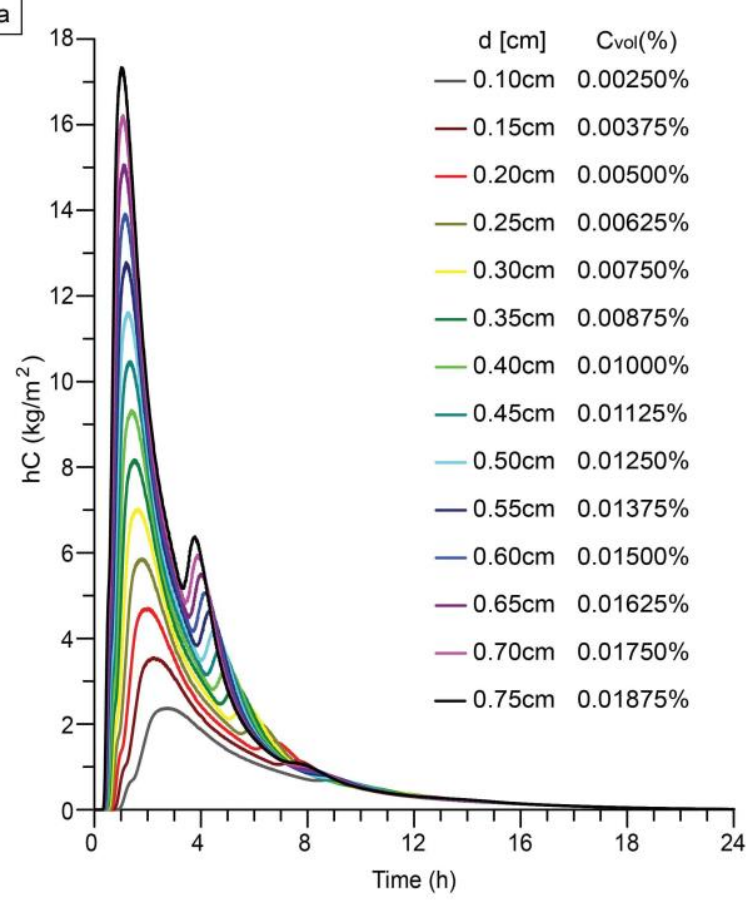

b
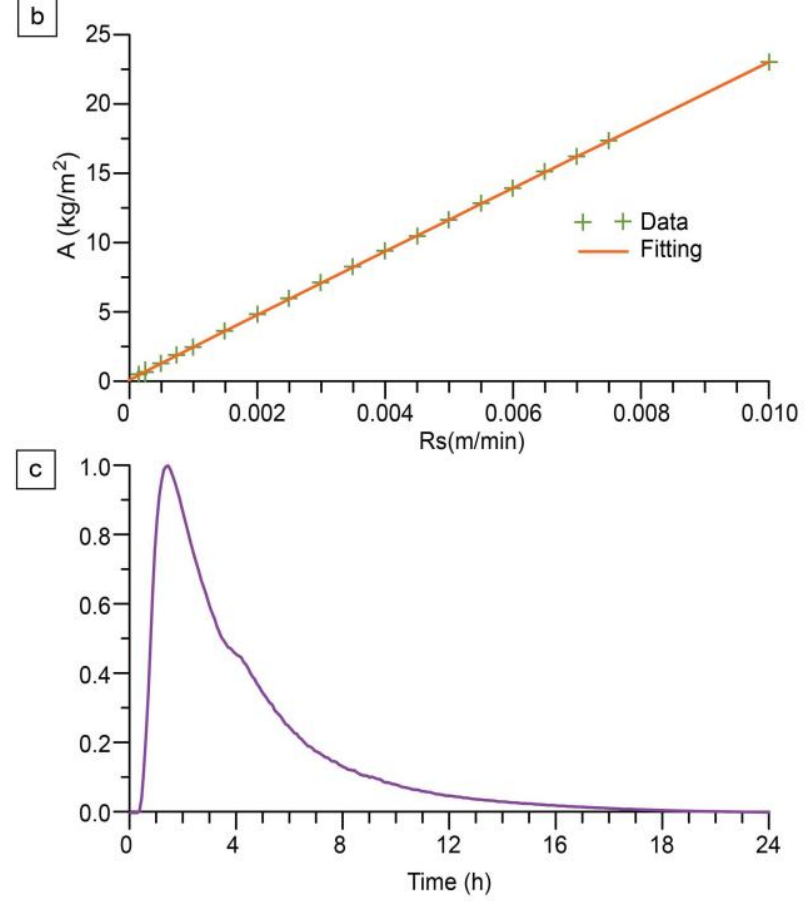

Figure 8 
Forcing over the fishing grounds
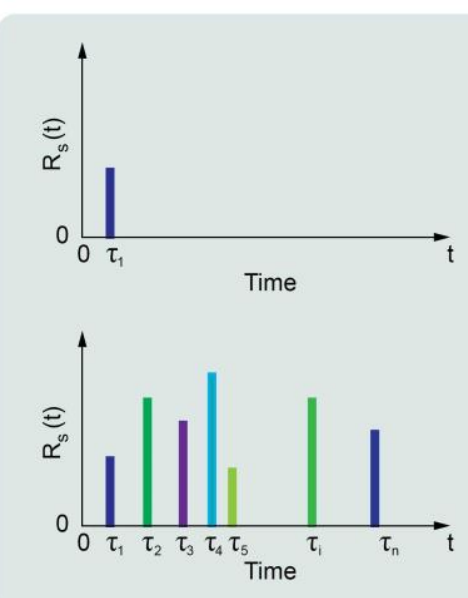

$R_{s}(t)$

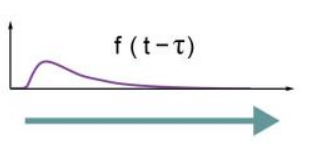

Response at the mooring site (MGM)
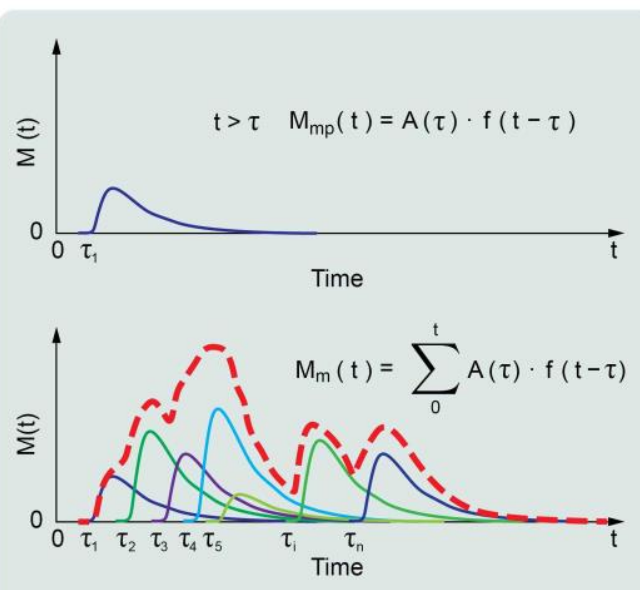

$A(\tau)$

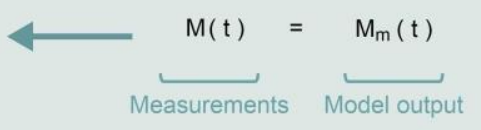

Figure 9 

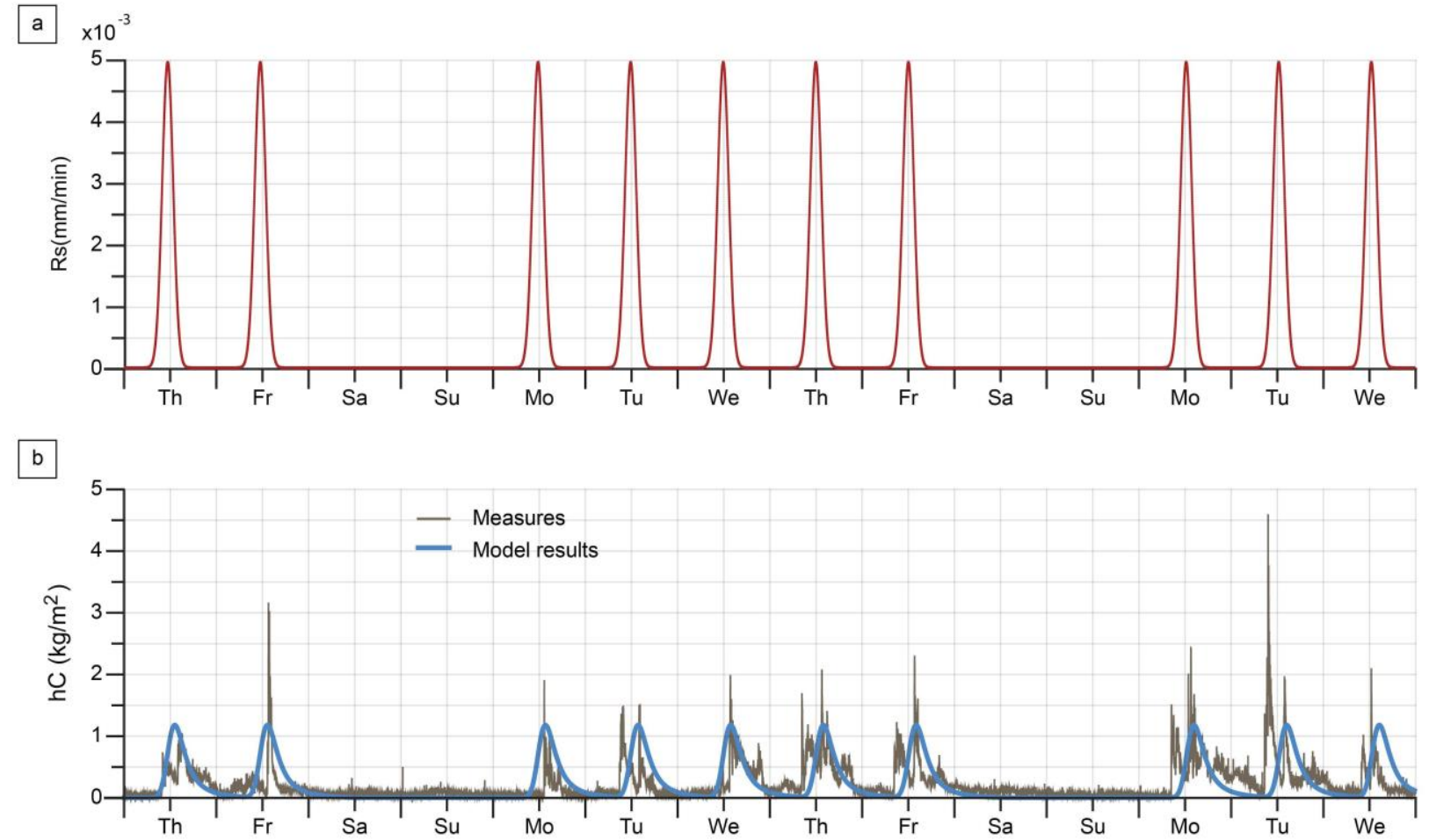

Figure 10 


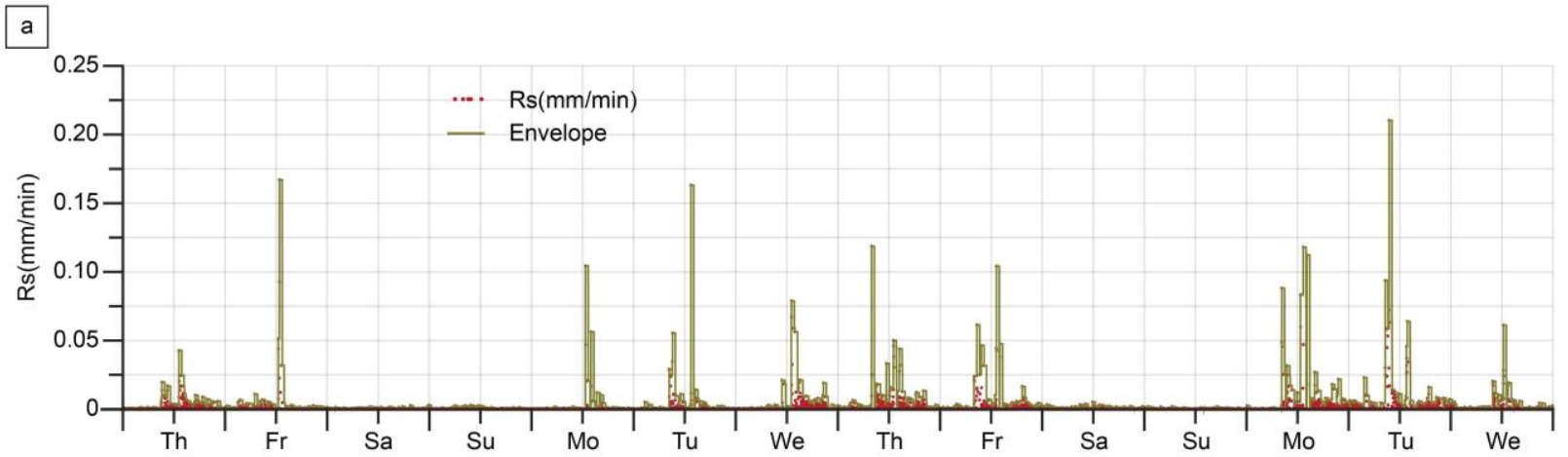

b

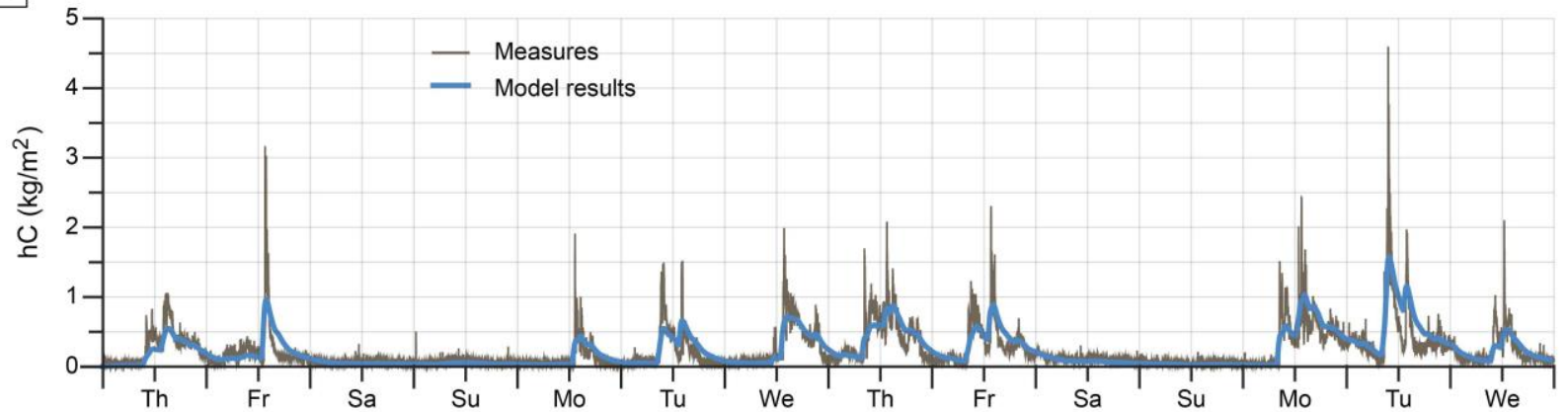

Figure 11 


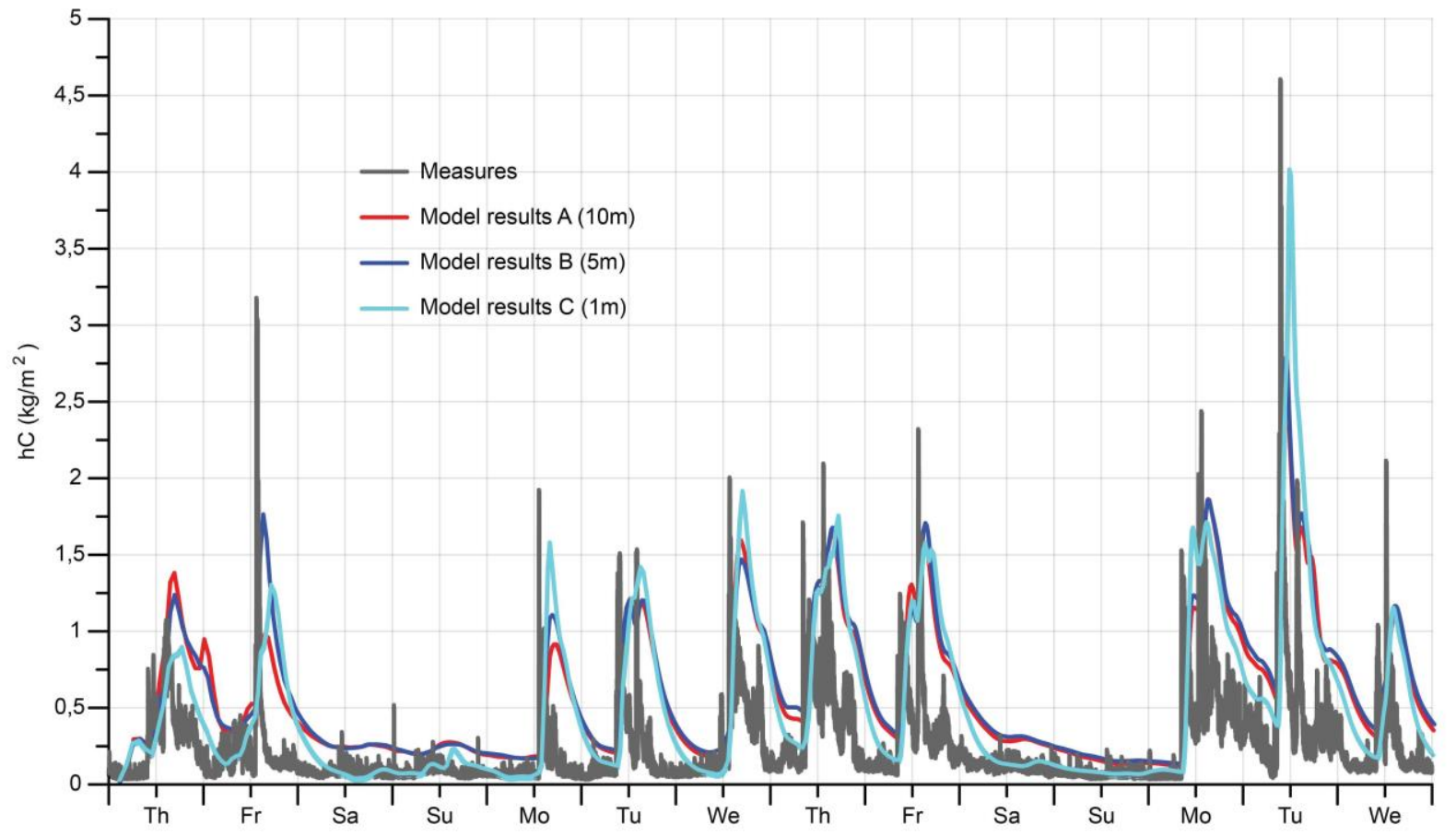

Figure 12 


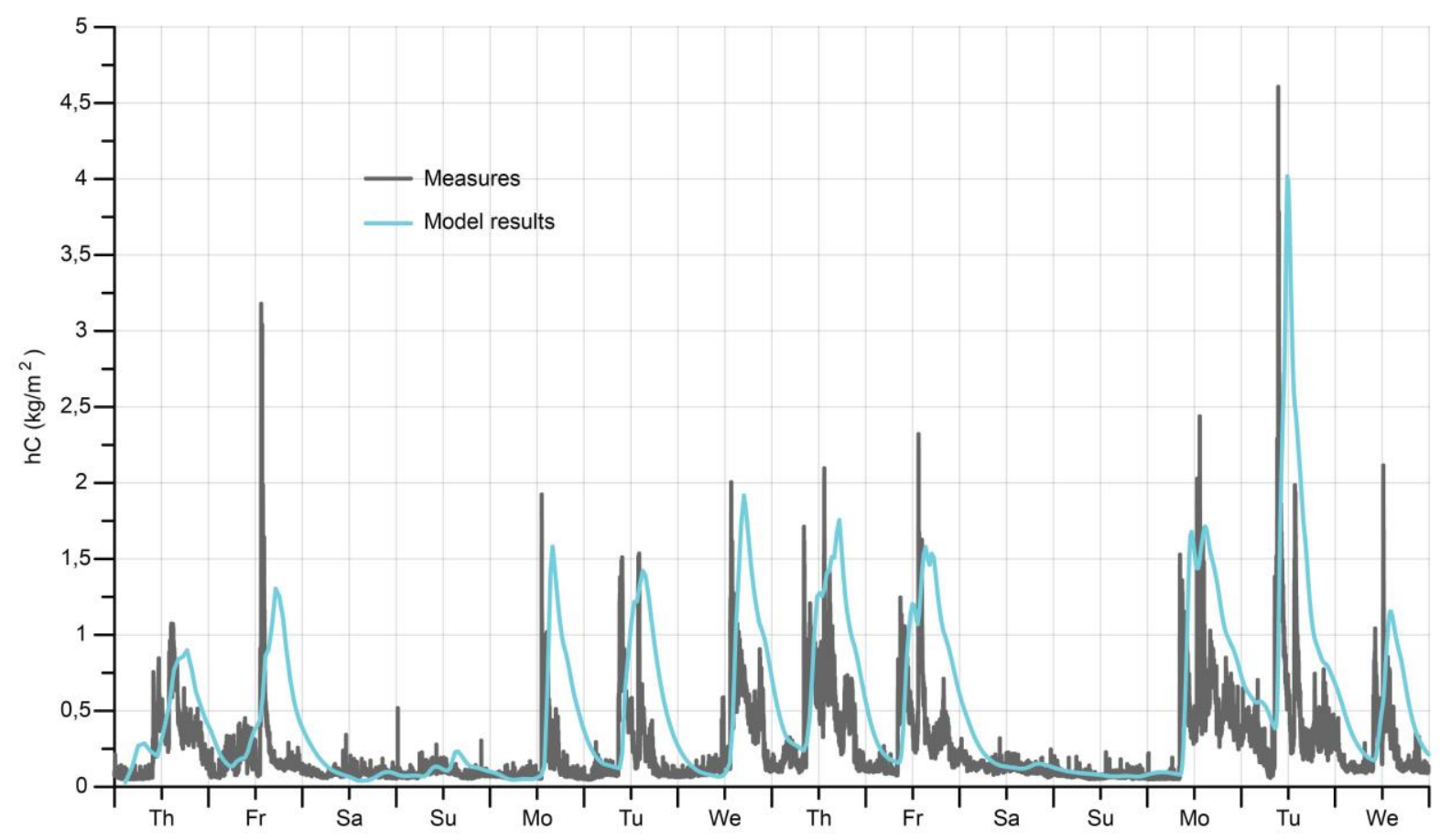

Figure 13 


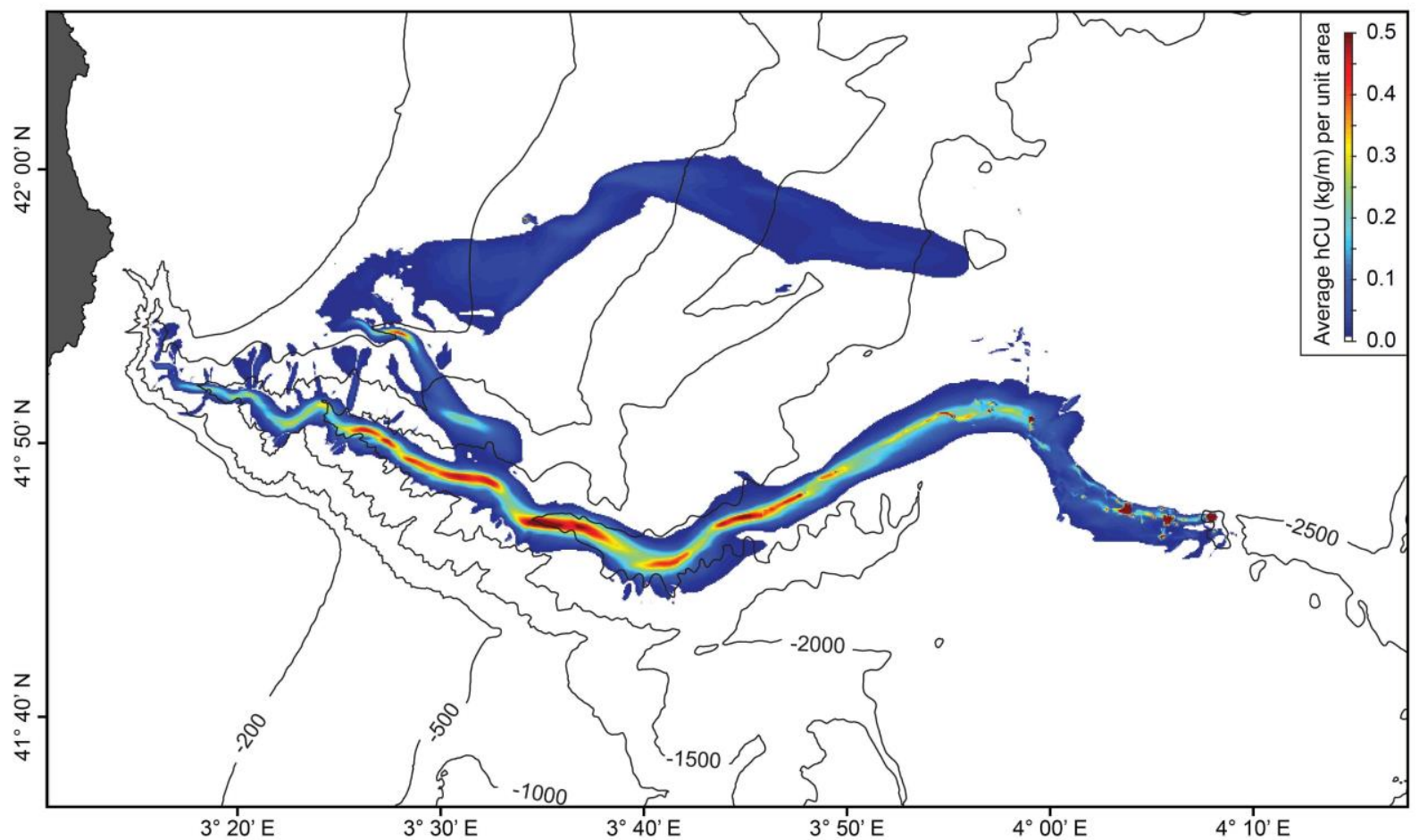

Figure 14 


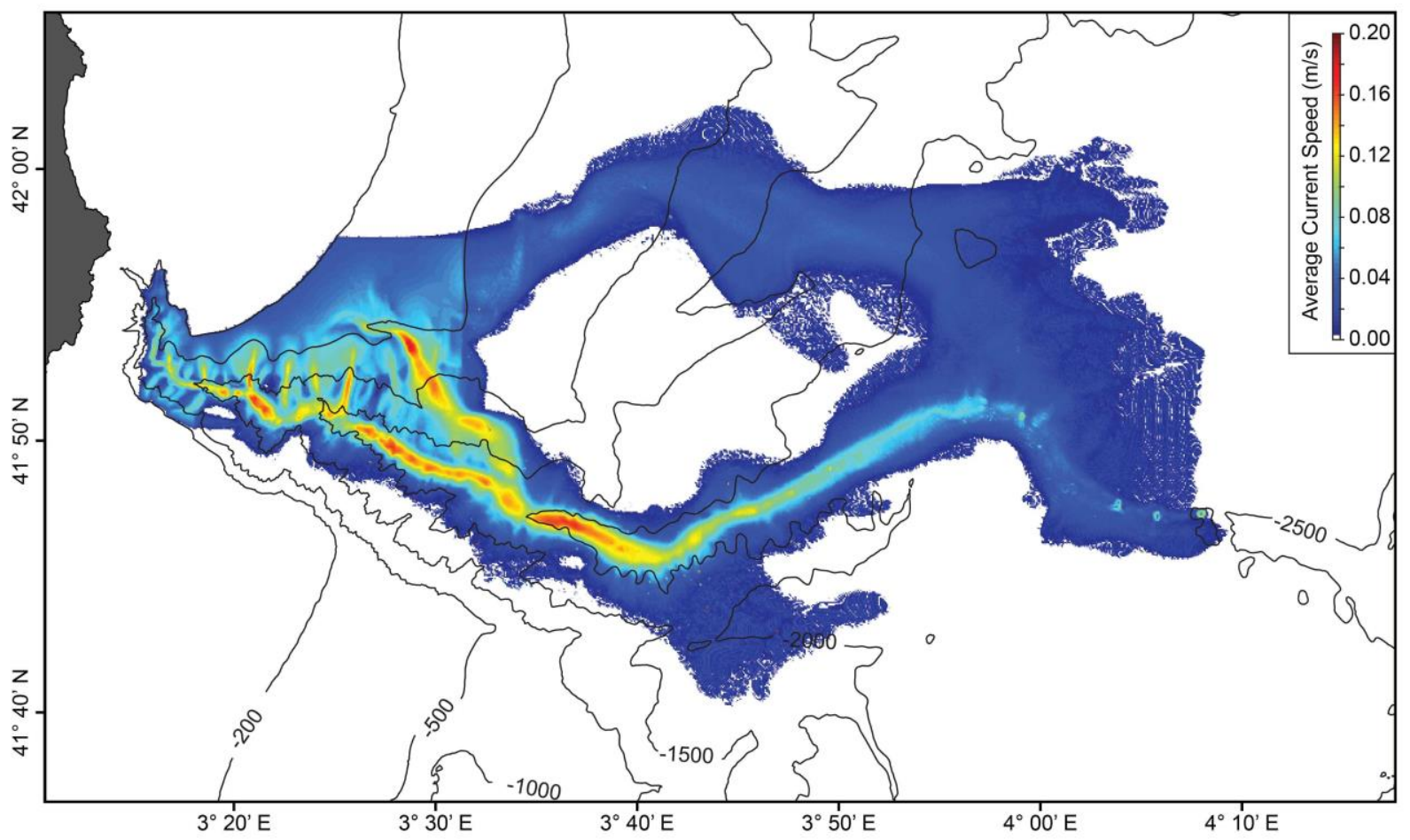

Figure 15 


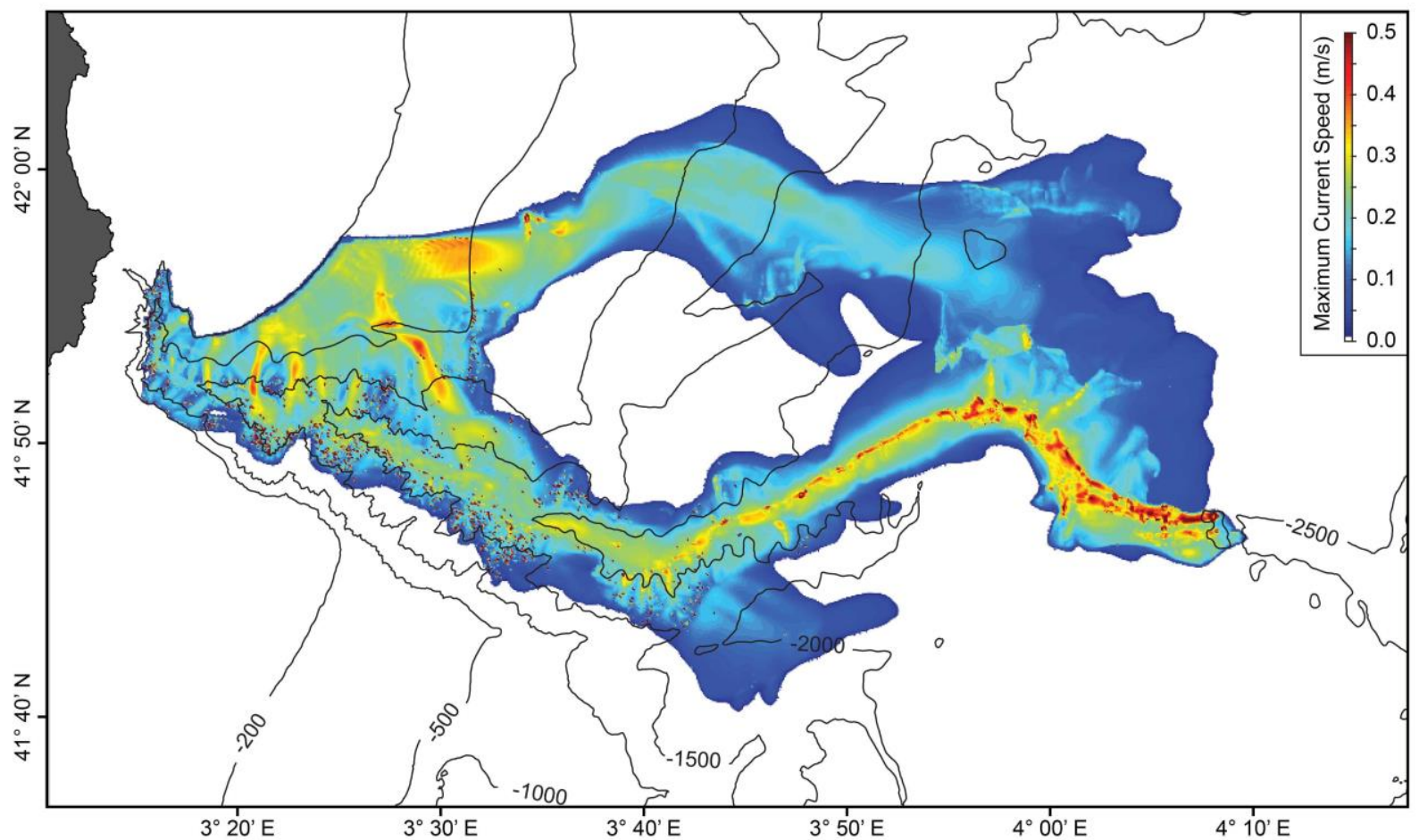

Figure 16 
a

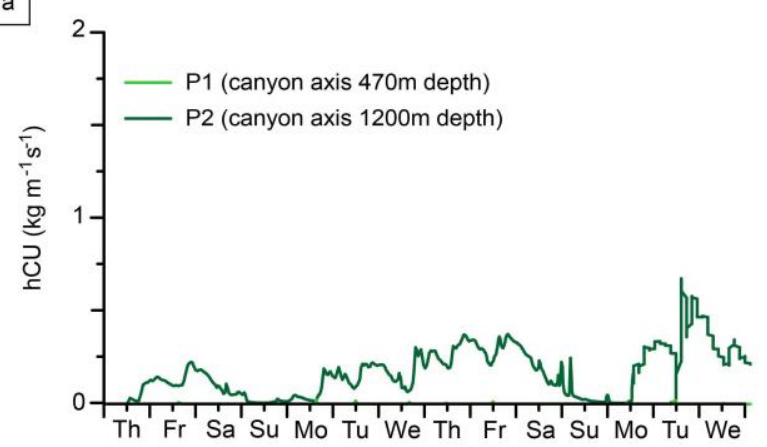

$b$

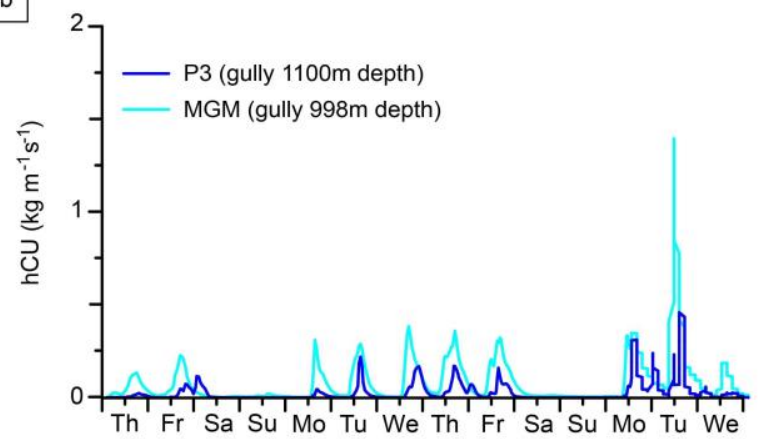

c

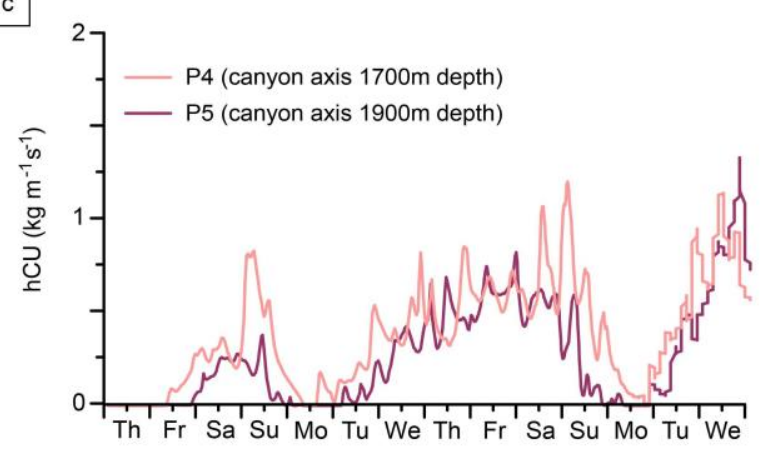

d

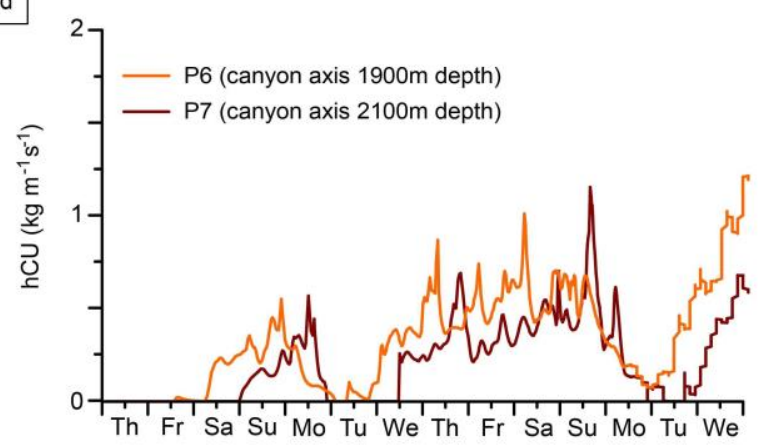

$a^{\prime}$

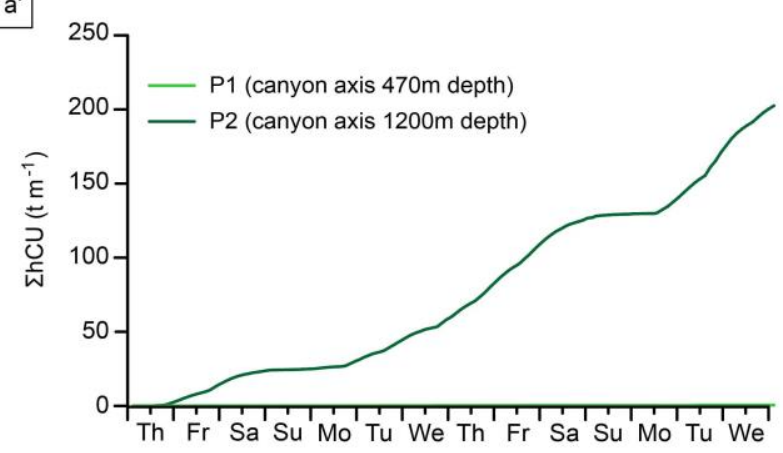

b'

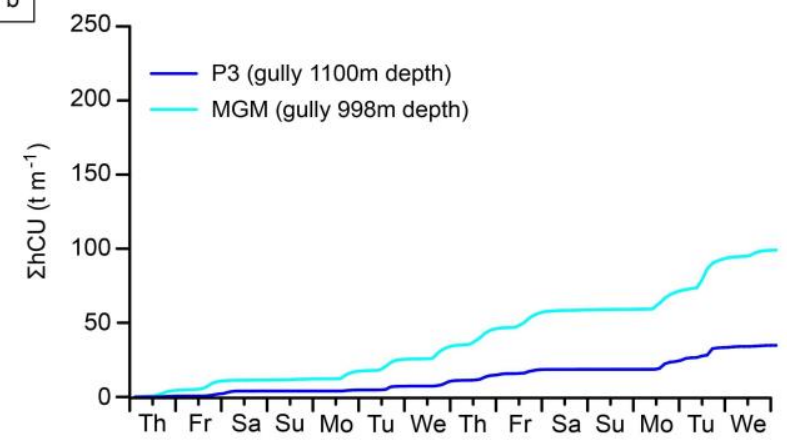

c'

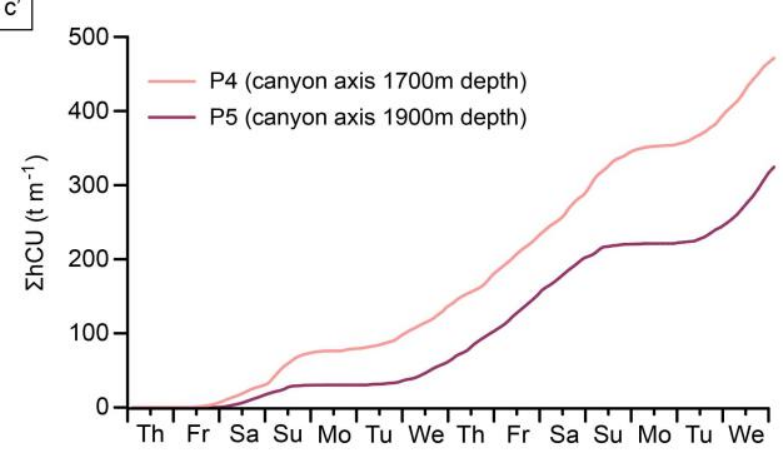

d'

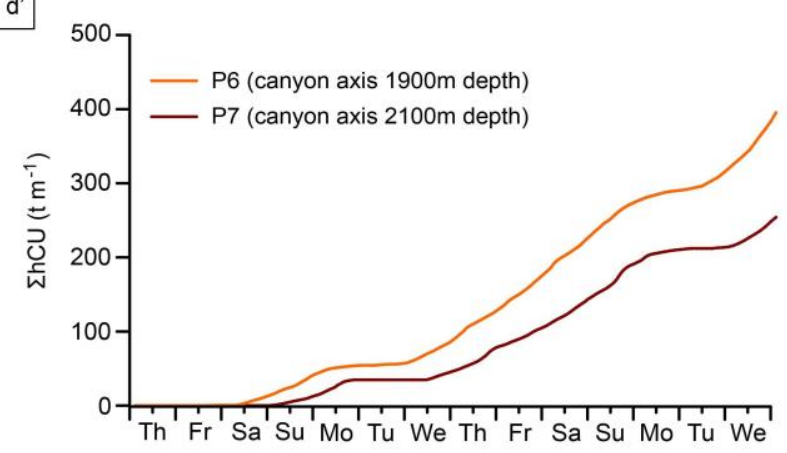

Figure 17 


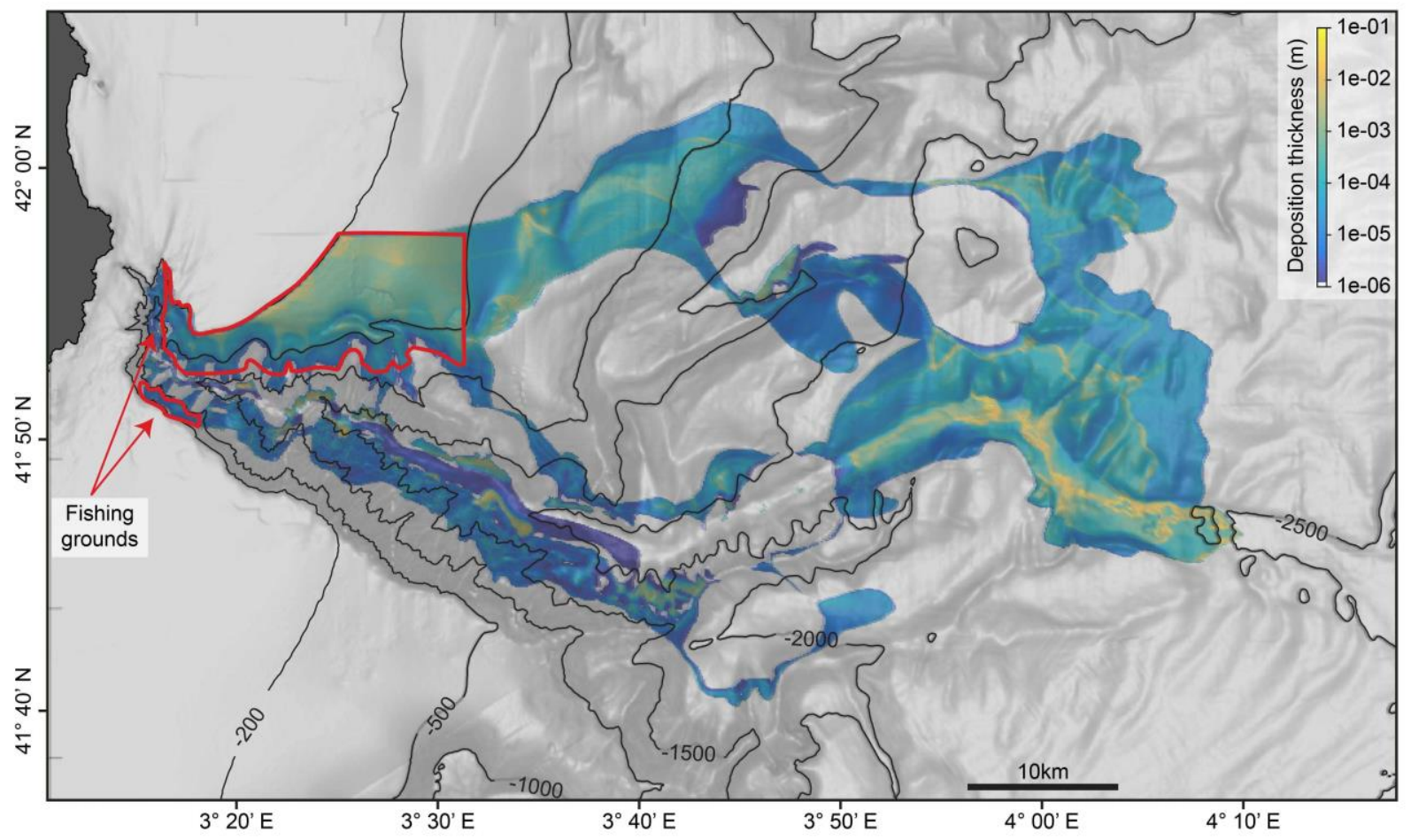

Figure 18 
Table 1

\begin{tabular}{|c|c|c|c|c|c|c|c|}
\hline $\begin{array}{c}\text { Control } \\
\text { point }\end{array}$ & Position & $\begin{array}{c}\text { Depth } \\
\text { (m) }\end{array}$ & $\begin{array}{c}\text { Averaged } \\
\text { Instantaneous } \\
\text { Sediment } \\
\text { Transport } \\
h C\left(\mathrm{~kg} / \mathrm{m}^{2}\right)\end{array}$ & $\begin{array}{c}\text { Maximum } \\
\text { Instantaneous } \\
\text { Sediment } \\
\text { Transport } \\
h C\left(\mathrm{~kg} / \mathrm{m}^{2}\right)\end{array}$ & $\begin{array}{l}\text { Averaged } \\
\text { Sediment } \\
\text { Transport } \\
h C U\left(\frac{k g}{m s}\right)\end{array}$ & $\begin{array}{l}\text { Maximum } \\
\text { Sediment } \\
\text { Transport } \\
h C U\left(\frac{k g}{m s}\right)\end{array}$ & $\begin{array}{c}\text { Cumulated } \\
\text { Sediment } \\
\text { Transport } \\
\text { (15 days) } \\
\int h C U d t\left(\frac{t}{m}\right)\end{array}$ \\
\hline $\mathrm{P} 1$ & Axis & 470 & 0.0046 & 0.1572 & 0.0003 & 0.0223 & 0.5338 \\
\hline $\mathrm{P} 2$ & Axis & 1200 & 1.3538 & 4.4973 & 0 & 0.6727 & 202.4391 \\
\hline MGM & Gully & 998 & 0.5712 & 3.9959 & 1011 & 1.3878 & 99.0080 \\
\hline P3 & Gully & 1100 & 0.2047 & 174 & 0.0343 & 0.4561 & 34.7561 \\
\hline $\mathrm{P} 4$ & Axis & 1700 & 2.7674 & 6.5637 & 0.44523 & 1.1986 & 471.1346 \\
\hline P5 & Axis & 1900 & 1.7890 & 5.7907 & 0.32583 & 1.3283 & 324.2193 \\
\hline P6 & Axis & 1900 & 2.2 & 6.2130 & 0.3931 & 1.2091 & 395.2138 \\
\hline P7 & Axis & 2100 & & 5.8954 & 0.2497 & 1.1485 & 254.0664 \\
\hline
\end{tabular}

